\title{
Daughters, Dowries, Deliveries: The Effect of Marital Payments on Fertility Choices in India
}

\author{
Marco Alfano* \\ Centre for Research and Analysis of Migration, \\ Department of Economics, University College London
}

September 2016

\begin{abstract}
This paper investigates the effect of the differential pecuniary costs of sons and daughters on fertility decisions. The focus is on dowries in India, which increase the economic returns to sons and decrease the returns to daughters. The paper exploits an exogenous shift in the cost of girls relative to boys arising from a revision in anti-dowry law, which is shown to have decreased dowry transfers markedly. The reform is found to have attenuated the widely documented positive association between daughters and their parents' fertility. The effect is particularly pronounced for more autonomous women and for individuals living in areas characterised by strong preferences for sons.
\end{abstract}

JEL Classifications: O15, J12, J13

Keywords: Dowry, Fertility, India, Son Preferences

*Contact: m.alfano@ucl.ac.uk, Department of Economics, University College London, Drayton House, London WC1H 0AX, UK. For helpful comments, I would like to thank Wiji Arulampalam, Golnaz Badkobeh, Sonia Bhalotra, Thomas Cornelissen, Christian Dustmann, Werner Menski, Luigi Minale, Robin Naylor, Anna Okatenko, Sarmistha Pal, Imran Rasul, Uta Schönberg, Jeremy Smith, Jan Stuhler and seminar participants at the Conference on Economics Aspects of Public Policy, CReAM, EALE, ESPE, IIES, NISER, SSEES, University of Essex and XII Brucchi Luchino Workshop. I gratefully acknowledge financial support from the British Academy and the Norface Research Programme on Migration. All errors are my own. 


\section{Introduction}

India is characterised by gender gaps in many human development indicators. Young girls, in particular, remain the most disadvantaged (The World Bank, 2012) and face significant disparities in a number of welfare measures such as mortality (Bhargava, 2003; Arnold et al., 2002), nutrition (Jayachandran and Kuziemko, 2011; Borooah, 2004) and child care (Barcellos et al., 2014). ${ }^{1}$ Gender biases are also reflected in parental fertility choices (Das, 1987; Basu and De Jong, 2010). After the birth of a daughter, parents have an incentive to give birth to another child in the hope of giving birth to a son (Arokiasamy, 2002). Such son-preferring gender biased stopping rules (Yamaguchi, 1989) have been shown to increase overall fertility (Seidl, 1995; Dreze and Murthi, 2001) and decrease young girls' welfare (Jensen, 2003). Whilst the presence of son-biased fertility stopping behaviour has been well documented, few analyses have tested the role of income or costs in generating such behaviour. ${ }^{2}$

This paper explores whether changes in the economic costs of daughters vis-à-vis sons affect their parents' fertility decisions. For most costs related to children, the gender specific component can be hard to determine. The paper addresses this measurement problem by focusing on a widespread custom in India: dowries, defined as marital transfers of resources from the family of the bride to the groom or his family (see Anderson, 2007a; for a review). Because of these payments, the birth of a girl is associated with a negative, and the birth of a boy with a positive, anticipated change in wealth at the time of his or her marriage. ${ }^{3}$ As a consequence, the overall cost of children depends on their total number as well as on their gender composition. Parents are likely to internalise this association and there is, in fact, qualitative evidence that dowries affect fertility choices (Diamond-Smith et al., 2008).

I start by documenting how parents condition their fertility choices on the sex mix of their offspring. For this, I estimate the likelihood that a woman gives birth in a given year as a function of individual controls and the gender composition of her children. The model is estimated using retrospective birth histories of women drawn from three rounds of the National Family Health Survey (NFHS, 1994; 1999; 2007b). The main specification approximates the gender composition of a woman's offspring by the gender of her first child (Dahl and Moretti, 2008), which is argued to be exogenous. Having a firstborn girl (compared to a firstborn boy) increases the subsequent annual hazard of a birth by around 2 percentage

\footnotetext{
${ }^{1}$ One prominent explanation amongst economists for such disparities is the fact that parents invest more heavily in boys than in girls (see Jensen, 2012; Qian, 2008; for recent examples).

${ }^{2}$ Jensen (2010), for example, further investigates the importance of future income streams for human capital investments.

${ }^{3}$ In India, parents can capture (at least) part of their son's dowry. See Rao (1993) for evidence.
} 
points, which is found to be comparable to a reduction of 4 years in maternal education. In additional specifications I use alternative measurements for the gender composition of children, such as the gender of the youngest child, the ratio of girls to boys or an indicator for whether girls outnumber boys. I find the same patterns.

To investigate how expected dowries influence the aforementioned fertility behaviour, this paper exploits a substantial revision in anti-dowry law. The Dowry Prohibition Rules (1985) tightened the monitoring of dowries and increased the penalties for offenders. Data from the Rural Economic and Demographic Survey (REDS, 1999) suggest that the introduction of the reform decreased dowry transfers by up to 7,500 rupees, which corresponds to around $45 \%$ of household income. ${ }^{4}$ The policy thus essentially lowered the cost of female births. Event study estimates further show that, for Hindus, the decrease in dowry payments occurred simultaneously with the introduction of the Dowry Prohibition Rules. By contrast, the dowry transfers of Muslims, who were exempt from the reform, did not change considerably in the years around the policy.

To evaluate the effect of the Dowry Prohibition Rules on reproductive behaviour, I analyse how the association between the sex mix of a woman's children and her fertility changes as a result of the reform. For this purpose, I first estimate the difference in fertility between women with a firstborn girl and a firstborn boy in the years preceding the policy. I then estimate the same parameter for the years after the policy and compare both coefficients using a difference in differences specification. To improve identification, I exploit the fact that marital transfers for Muslims were exempt from the anti-dowry law and compare the fertility behaviour of Hindus and Muslims in a triple differences framework.

The results suggest that the Dowry Prohibition Rules caused parents to become more indifferent to the gender of their children. In the years before the policy, women with a firstborn daughter were 2.5 percentage points more likely to have another child. After the reform, this association decreased to 0.6 percentage points. This corresponds to a decrease of around $25 \%$. The results also show that the policy had a strong impact on Hindus but no effect on Muslims. I also evaluate the policy using the three alternative measures of children's gender compositions mentioned above. ${ }^{5}$ The results do not change. The effect appears particularly strong for more autonomous women and for individuals living in areas characterised by strong preferences for sons.

To address the issue of possible confounding factors, I investigate the exact timing of births in an event study framework and find that the change in fertility behaviour occurred

\footnotetext{
${ }^{4}$ As reported by the REDS 1999.

${ }^{5}$ Recall, these are the gender of the youngest child, the ratio of girls to boys or an indicator for whether girls outnumber boys.
} 
one year after the introduction of the reform. ${ }^{6}$ Moreover, I exploit amendments to anti-dowry laws carried out by a subset of states in 1975/76. ${ }^{7}$ These changes decreased the impact of the Dowry Prohibition Rules considerably and the results show that the Rules only impacted the fertility behaviour of women residing in states that did not carry out the aforementioned amendments. Finally, I test whether the reform led parents to abort female foetuses and find no effect of the Dowry Prohibition Rules on sex ratios at birth.

This study aims to add to the growing knowledge base on dowries and marriage institutions. Both the economic rationale behind dowries (Ambrus et al., 2010; Bloch et al., 2004; Botticini and Siow, 2003) and the effect of marital institutions on women (Brown, 2009; Bloch and Rao, 2002) have received growing attention. By relating dowry payments to fertility decisions, this paper puts forward an explanation for son preferring stopping behaviour, which does not rely on parental preferences regarding a child's gender.

The remainder of the paper is structured as follows: Section 2 explains the practice of dowries and the legal framework. Section 3 introduces the data and gives motivating descriptive evidence. Section 4 lays out the empirical strategy the results of which are discussed in section 5. Section 6 addresses empirical concerns and section 7 concludes.

\section{Dowries in India}

At many Indian weddings, the parents of the bride pay a dowry to the groom or his family. Between the 1960s and 1990s, around $90 \%$ of marriages were accompanied by dowry payments (Anderson, 2007a). From a theoretical point of view, Anderson (2003) maintains that the prevalence of dowries in India is a result of fast economic development combined with the rigid social system provided by the country's caste system. Do et al. (2013) and Tertilt (2005) consider the importance of marriage patterns; Roy (2011); Dalmia (2004); Deolalikar and Rao (1998) focus on the characteristics of the groom, Caldwell et al. (1983) on the ones of the bride.

A considerable body of research has investigated the size of dowry transfers. Rao (2000) and Rao (1993) suggest these transfers to be considerable and increasing over time. Other research, by contrast, has put forward much lower figures (Arunachalam and Logan, 2008; Anderson, 2007b; Edlund, 2000). In particular, Edlund (2006) distinguishes gross from net dowry payments and argues that the increase in net dowries has been negligible. The survey carried out by the International Crops Research Institute for the Semi-Arid Tropics (ICRISAT) provides information on dowry payments before the year 1984, just before the

\footnotetext{
${ }^{6}$ This accounts for the duration of pregnancy.

${ }^{7}$ The states are Bihar, Haryana, Himachal Pradesh, Jammu and Kashmir and Punjab.
} 
tightening of dowry laws. ${ }^{8}$ Around $80 \%$ of marriages before the year 1983 involved a dowry payment. The net value of these payments ${ }^{9}$ was around 4,800 Rupees, which corresponds to circa $68 \%$ of total household assets before marriage (Rao, 1993).

\subsection{Dowry Laws in India}

To analyse the effect of expected dowries on fertility, I exploit an exogenous decrease in dowries parents expect to pay resulting from the introduction of anti-dowry law. In an attempt to curb the prevalence of dowries, the government of India passed the Dowry Prohibition Act in 1961 prohibiting the giving and taking of dowry (Dowry Prohibition Act, 1961). ${ }^{10}$ Despite this legislation few dowry cases reached the courts and the practice of dowries persisted. A common reason put forward for this is that the 1961 Act's provisions were not strong enough to implement successful prosecutions (Chowdhary, 1998).

In 1985, the goverment of India tightened the Dowry Prohibition Act by introducing the Dowry Prohibition Rules (1985), ${ }^{11}$ which are the focus of this empirical analysis. The purpose of this amendment was to make the Dowry Prohibition Act of 1961 more stringent and effective in a number of ways. First, the legislation establishes a set of rules in accordance with which a list of presents has to be maintained. The list of presents given to be bride is kept by the bride whereas the list containing presents to the groom is kept with the groom. These lists must be in writing and contain the approximate value of the present. Second, the Dowry Prohibition Rules raise the minimum punishment for taking or abetting the taking of dowry to 5 years of imprisonment and to a fine of 15,000 Rupees. ${ }^{12}$ Third, the burden of proving that no funds were exchanged now lies with the person who takes or abets the taking of dowry. Fourth, offences to the act are made non-bailable. The act does not apply to marital payments of Muslims.

The tightening of dowry laws was a direct result of lobbying by feminist groups in Delhi (see Majumdar, 2005; for a detailed historical overview). In the late 1970s and early 1980s, activist groups in the capital protested against the rising number of deaths of newly married

\footnotetext{
${ }^{8}$ The survey is carried out in 6 different villages in the Indian state of Andhra Pradesh between the years 1975 and 1984. These data have frequently been used in previous studies and the timing is fortunate since the last survey coincides with the year immediately before the policy. This survey contains self-reported information on, inter alia, age, marital status of all household members and inventory files for current physical stocks as well as on financial assets and liabilities such as bank accounts and dowries.

${ }^{9}$ Defined as transfers received by the grooms minus transfers paid.

${ }^{10}$ Dowry is defined as any property or valuable security given or agreed to be given either directly or indirectly a) by one party to a marriage to the other party to the marriage or b) by the parents of either party to a marriage or by any other person to either part to the marriage or to any other person at or before or any time after the marriage in connection with the marriage of said parties.

${ }^{11}$ Amendment Act 63 of 1984 came into force on the 2.10.1985.

${ }^{12}$ According to the 1961 Act, the punishment was either 6 months in prison or a fine of 5,000 rupees.
} 
women, especially as a result of accidental fires, which they attributed to the scarce implementation of the Dowry Prohibition Act. As a response, in 1982, the Joint Committee of the Houses commissioned an internal report entitled "Dowry Deaths and Law Reform". It concluded that the government should revise the Dowry Prohibition Act. The fact that the change in dowry laws resulted from lobbying concentrated in the capital city suggests that the tightening of the law did not reflect general trends in Indian society.

To facilitate the implementation of the newly established rules, the amended act introduced the Dowry Prohibition Officers. The tasks of these public sector employees included the prevention of the taking and demanding of dowries and the collection of evidence necessary for the prosecution of persons committing offences under the Dowry Prohibition Act. ${ }^{13}$ Legal research has pointed to a marked increase in dowry cases heard by courts in the mid 1980s (Menksi, 1998). Overall, the new rules were perceived by many as countering the prevalent attitude of patriarchal traditions that women were owned by men.

Figure 1: Official crime statistics on dowries

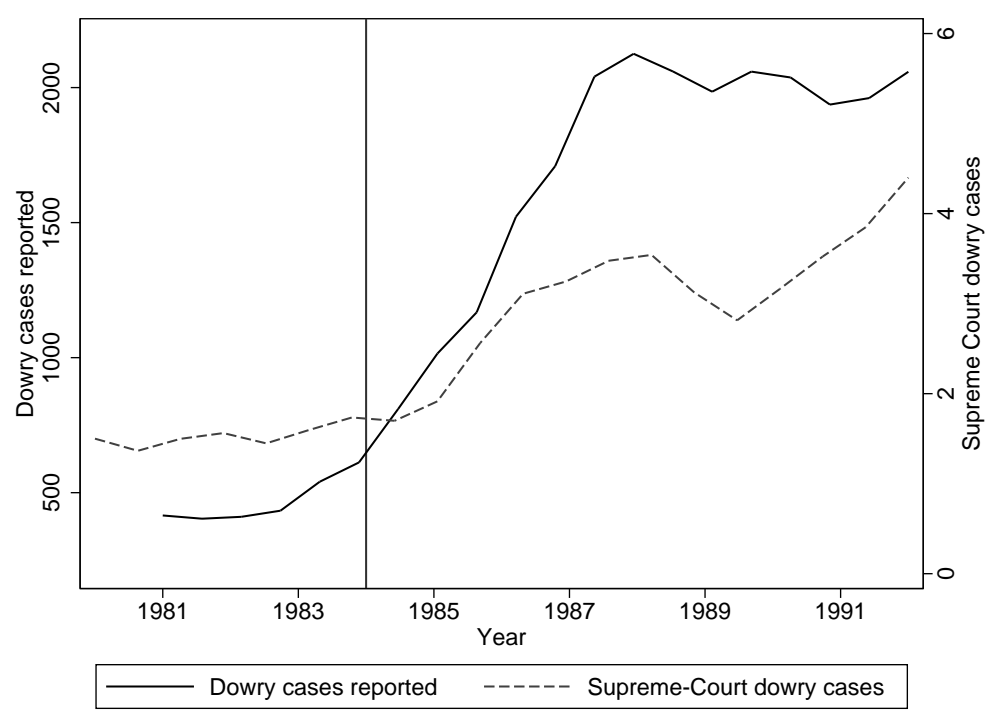

Notes: Figure reports dowry cases in India by year; the solid line shows dowry cases reported to Indian authorities and refers to the left vertical axis, data are drawn from the National Crime Reference Bureau of India; the dashed line shows judgements of the Supreme Court of India and refers to the right vertical axis, Supreme Court judgements were digitised from the All India Reporter.

Indian crime statistics suggest that the introduction of the Dowry Prohibition Rules led to a marked increase in the number of convicted dowry offenders. The solid line in figure 1 plots the number of reported dowry cases by year as collected by the National Crime Reference

\footnotetext{
${ }^{13}$ Section $8 \mathrm{~B}$ of the amended Dowry Prohibition Act.
} 
Bureau (NCRB). ${ }^{14}$ Whilst the number of dowry cases reported prior to the Dowry Prohibition Rules is around 400 per year, the figures increase markedly in the years around the policy reaching around 2,000 for 1987 and subsequent years. The Dowry Prohibition Rules also led to an increase in dowry cases heard by the Supreme Court of India. ${ }^{15}$ The dashed line in figure 1 reports the number Supreme Court judgements concerning dowries. In the early 1980s, the average number of dowry judgments per year was around two, which doubled to around four in the years after the policy change. Because of their public coverage, Supreme Court judgements are likely to be particularly important for individuals' expectations regarding dowry payments.

\subsection{The Impact of the Dowry Prohibition Rules}

Evidence from the 1999 round of the Rural Economic and Demographic Survey (REDS, 1999) suggests that the Dowry Prohibition Rules led to a marked decrease in dowry payments. The REDS data are a nationally representative rural sample of Indian households. ${ }^{16}$ This paper uses data from the 1999 round, which contains retrospective information on year of marriage and dowry transfers. I select women born 1955 to 1975 who married between the years 1975 and 1995. The sample consists of 10,201 individuals, who were aged around 20 at the time of the policy change. Around $52 \%$ of women have primary education or higher, $8 \%$ of households are Muslim and $12 \%$ belong to a scheduled caste. The average household income is around 16,000 rupees (in 1985 prices) and around 77\% of households report owning land. The average dowry for individuals married before the year 1985 was around 13,000 rupees (in 1985 prices). The standard deviation of dowries paid before the policy is around 22,000 rupees. This large variation reflects the well-known fact that measuring dowries accurately is challenging (see Anderson, 2007a; for an overview).

Panel a of figure 2 reports the average value of real dowry transfers by year of marriage. ${ }^{17}$ Because of the considerable variance in dowry payments mentioned above, panel a reports polynomially smoothed estimates of mean dowries. In the years before the policy, the average amount of dowries fluctuates between 13,000 and 14,000 rupees. Between the years 1986 and

\footnotetext{
${ }^{14}$ The NCRB reports the number of dowry cases in its yearly publication Crime in India (National Crime Reference Bureau, 1992). Data on crime statistics have been complemented with information taken from Gosh (1993) and Kumar Gandhi (1985).

${ }^{15}$ The number of Supreme Court judgments was collected by digitising cases reported in the All India Reporter.

${ }^{16}$ The data contain detailed information on economic, demographic and village level variables. Households were first interviewed in 1969, 1970, 1971, 1982, 1999 and 2006. The data are publicly available at http://adfdell.pstc.brown.edu.

${ }^{17}$ Dowries are reported in 1985 prices. To deflate dowry transfers, I use the Consumer Price Index for Agricultural Workers since the REDS is a rural sample. The deflating values are obtained from the EOOP Indian States Dataset at http://sticerd.1se.ac.uk/eopp/_new/data/indian_data/default.asp.
} 
1990 there is a sharp decrease to around 9,000 rupees. Dowry transfers in subsequent years stabilise around that value. These unconditional means suggest that the Dowry Prohibition Rules decreased dowry payments by around 4,000 rupees, which corresponds to around $25 \%$ of household income (as reported by the REDS).

Figure 2: Dowry payments by year of marriage and year of birth

(a) Mean dowries in India

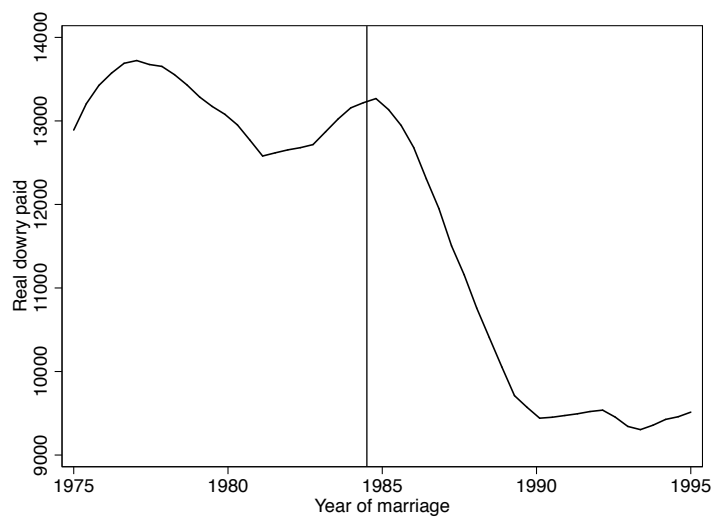

(b) Year of marriage dummies

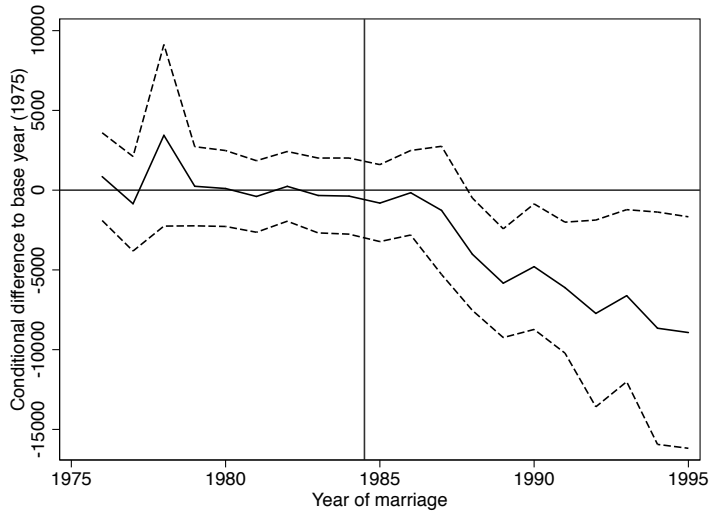

(c) Year of birth dummies

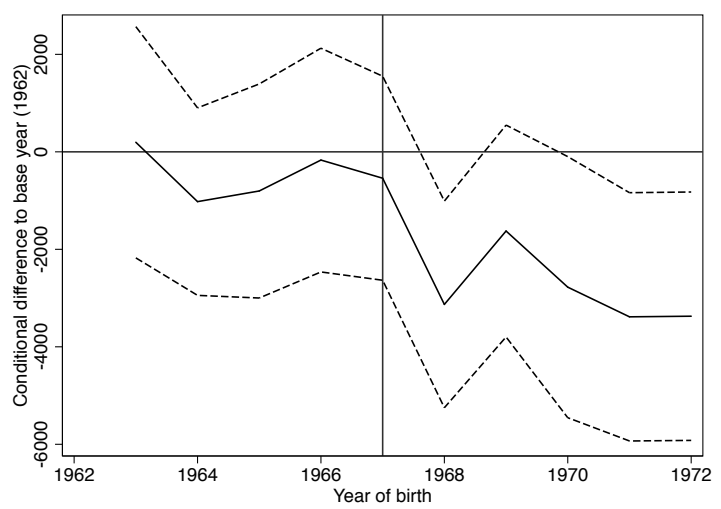

Notes: Figure reports dowry payments by year of marriage and year of birth in India; all dowries are reported in 1985 prices; if no dowry is transferred, real dowries are coded as zero; Panel a: solid line shows polynomially smoothed mean of dowry paid by year of marriage for the whole of India, the bandwidth of the smoother is 1.4; Panel b: reports ordinary least squares estimates for regression of dowry payments on year of marriage; the base year is 1975; Panel c: reports ordinary least squares estimates on year of birth dummies; the base year is 1962; solid lines denote point estimates, dashed lines $95 \%$ confidence intervals; standard errors are clustered at state level; data are drawn from 1999 round of REDS; sample consists of women born 1955 - 1975 married between 1975 and 1995.

I test whether the post-1985 decrease in dowry payments is robust to controlling for female and family characteristics by estimating the following equation 


$$
d_{i s m}=X_{i s m} \beta+\alpha_{s}+\sum_{m=1976}^{1995} \mu_{m} I_{m}+\epsilon_{i s m}
$$

where $d_{i s m}$ is the dowry paid by woman $i$ residing in state $s$ married in year $m$; $X_{i s m}$ is a vector of female and family characteristics, ${ }^{18} \alpha_{s}$ a state fixed effect and $I_{m}=1$ if woman $i$ married in year $m$. Panel b of figure 2 reports the point estimates for $\mu_{m}$ (solid line) along with their $95 \%$ confidence intervals (dashed line). Conditional dowry payments in the years prior to 1985 are similar to the base year, 1975. The point estimates fluctuate around zero and are not statistically different from zero. After the policy, however, the estimates drop significantly. Conditional dowry payments in the late 1980s and early 1990s are between 5,000 and 7,500 rupees lower compared to the base year. For these years the estimates are statistically different from zero. The decrease corresponds to around $30 \%-45 \%$ of household income.

A possible concern with the the relationship between year of marriage and dowry payments is that households intending to pay high dowries could have anticipated the reform and married their daughters before the change in the law. To address this concern, I estimate marital transfers as a function of a woman's year of birth rather than her year of marriage. For the sample under consideration, more than half of women marry between the ages of 17 and 20. As a consequence, the Dowry Prohibition Rules should have a stronger impact on women born 1968 or younger. Individuals born before 1968, by contrast, should remain relatively unaffected. Panel c of figure 2 plots the estimates for the parameters on the year of birth dummies. For individuals born between 1963 and 1967 dowry payments are very similar to the base year, 1962. By contrast, conditional payments for women born between 1968 and 1972 decrease by between 2,000 and 4,000 rupees. For this cohort the point estimates are significantly different from zero.

To investigate the importance of possible confounding factors, I exploit the fact that exposure to the Dowry Prohibition Rules varied by two factors. First, recall that marital transfers for Muslims were exempt from the reform (see section 2.1). Second, in the years 1975 and 1976, the states of Bihar, Haryana, Himachal Pradesh and Punjab implemented state amendments to the Dowry Prohibition Act (1961), which considerably decreased the impact of the Dowry Prohibition Rules (1985) for numerous reasons. ${ }^{19}$ The states are shown in panel a of figure 3. The legislations anticipated many changes later to be implemented

\footnotetext{
${ }^{18}$ The covariates include woman $i$ 's year of birth, her education, her partner's education, a Hindu dummy, the number of household members, a dummy for whether the household owns land, household income and caste.

${ }^{19}$ Jammu and Kashmir were exempt from the Dowry Prohibition Act. For the fertility estimates, I added Jammu and Kashmir to the amended states since the Dowry Prohibition Rules had no impact in this state.
} 
by the Dowry Prohibition Rules. As a consequence, women in these states were subject to stricter dowry laws ten years earlier than the rest of the country and the relative change in legislation brought about by the Dowry Prohibition Rules was less pronounced. In the first instance, the amendments increased the penalties for giving and receiving a dowry. Whereas the 1961 act stipulated that dowries could be punished either by a fine of 5,000 rupees or by a prison sentence of up to 6 months, the changes introduced a mandatory prison sentence in all states. In some cases, the duration of this sentence was increased to one year. ${ }^{20}$ Penalties for demanding a dowry were increased accordingly. The amendments also changed the legal definition of dowries so as to ease the monitoring of marital transfers by the authorities. ${ }^{21}$ The revised definitions included details on wedding expenses and covered other ceremonies. ${ }^{22}$ Finally, in most instances, dowry offences were made cognizable, bailable and non-compoundable.

Women residing in states that carried out amendments to their dowry laws were less affected by the Dowry Prohibition Rules for a further, perhaps more important, reason. The Indian constitution does not specify whether a state legislation overrides a central act or vice versa. Because of this, dowry offenders caught after 1985 could be prosecuted either by the newly established Dowry Prohibition Rules or by the state amendment introduced 10 years earlier. The resulting ambiguity regarding the application of dowry laws reduced the impact of the Dowry Prohibition Rules further. Immediately after the implementation of the changes in 1975/76, the central government retained the right to change the amendments for two consecutive legislative sessions. No changes were repealed and the laws remained in force after the introduction of the Dowry Prohibition Rules. In fact, legal research shows that state amendments were still widely applied even after 1985 (see Bhatnagar, J. P., 1988; Diwan, Paras, 1990; Aiyer, K and Tripathi, S. L., 1998, for details and case studies).

Descriptive evidence suggests that the impact of the Dowry Prohibition Rules on dowry payments varied considerably by both religion and administrative area. Panel b of figure 3 reports the smoothed mean real dowry payments by year of marriage for the whole of India distinguishing by religion. Before 1985, dowries paid by Hindus (solid line) by far exceeded the ones of Muslims (dashed line). After the reform, however, marital payments decreased markedly for the former and remained essentially unchanged for the latter. Panels c and d report the smoothed mean real dowry payments splitting the sample by states that did not amend anti-dowry law (unamended states) and states that did (amended states) respectively. The two figures show that, after the reform, dowry payments decreased markedly only for

\footnotetext{
${ }^{20}$ As in Punjab for instance.

${ }^{21}$ The problem of the vague definition of dowries was already highlighted by (Chowdhary, 1998).

${ }^{22}$ Such as Thakka, Sagai, Tikka Shagun and Milni.
} 
Figure 3: Dowry payments by year of marriage - Amended and Unamended states

(a) Location of amended states

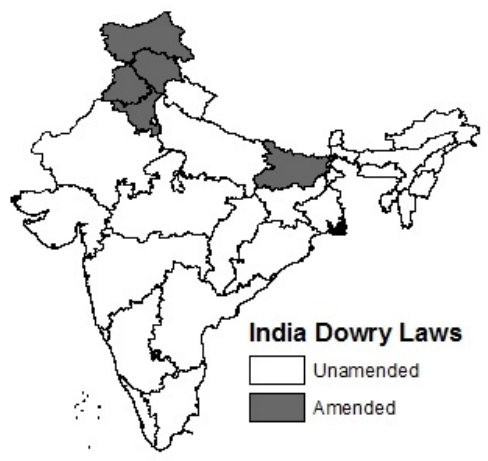

(c) Mean dowries in unamended states

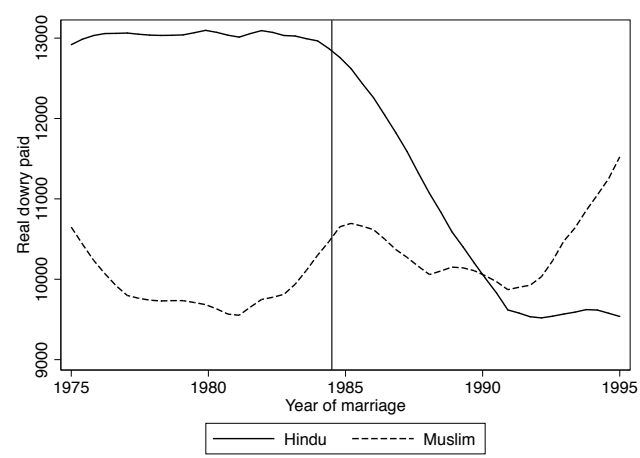

(b) Mean dowries in India

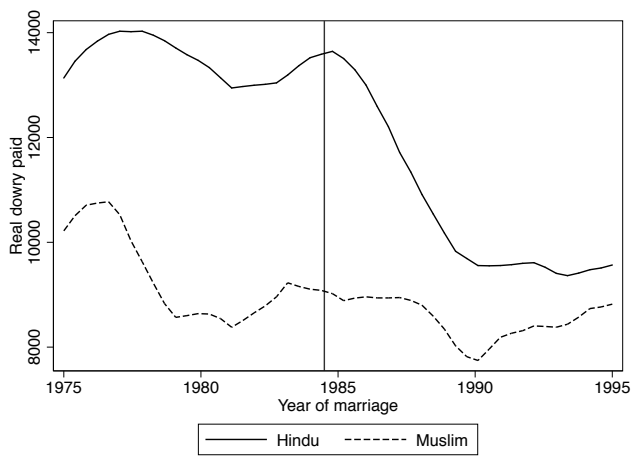

(d) Mean dowries in amended states

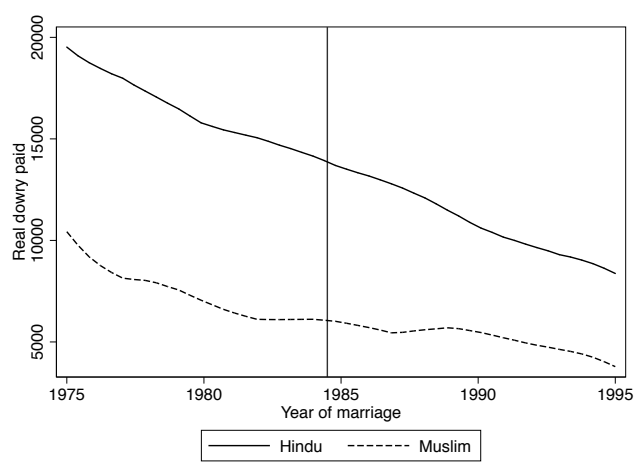

Notes: Panel a shows geographic location of amended states (Bihar, Haryana, Himachal Pradesh and Punjab) with addition of Jammu and Kashmir; Remaining panels report dowry payments by year of marriage in India; lines show polynomially smoothed mean of dowry paid by year of marriage for Hindus (solid line) and Muslims (dashed line); all dowries are reported in 1985 prices; Panel b: the sample refers to whole of India, polynomial smoother has bandwidth 1.4; Panel c: the sample refers to unamended states, polynomial smoother has bandwidth 2.2; Panel d: the sample refers to amended states, polynomial smoother has bandwidth 2.2; sample consists of women born 1955 - 1975 married between 1975 and 1995 from REDS.

Hindus living in unamended states. For Muslims living in the same area, marital payments do not change significantly. For individuals living in amended states shown in panel d, dowries for both Hindus and Muslims do not change significantly around the year of the reform. Although both lines show a decreasing trend, the two figures appear almost parallel. It should be noted here that dowry payments (especially in panel c and $\mathrm{d}$ ) exhibit some degree of fluctuations. This is most likely due to the fact that the sample sizes for the finer cells become relatively small. Moreover, as mentioned above, dowries are often measured with error (see Anderson, 2007a; for an overview).

To further investigate the impact of the reform, I estimate a difference in differences framework, which uses the aforementioned variations. The model regresses the dependent 
variable in equation $1, d_{i s m}$, on a Hindu dummy, year of marriage dummies and the interaction term between the Hindu dummy and an indicator variable taking the value 1 if woman $i$ married in the year 1985 or after, Post $1 .{ }^{23}$ Columns 1 and 2 of table 1 report the parameters for this specification. The first column estimates the difference in differences specification for women residing in states that amended anti-dowry laws in 1975/6. For this sample, there is no significant impact of the Dowry Prohibition Rules. By contrast, the estimates for the sample of women in unamended states (column 2) show that the Dowry Prohibition Rules decreased dowry payments by around 1,500 rupees. In this case the estimate is statistically significantly different from zero.

As mentioned before, parents may have anticipated the Dowry Prohibition Rules and may thus have changed their daughters' wedding date. To address this concern, I re-estimate the difference in differences specification using woman $i$ 's year of birth rather than year of marriage. In this case, the Post2 dummy takes the value 1 if woman $i$ was born after the year 1968. The parameter estimates in columns 3 and 4 paint a similar picture. In states that amended anti-dowry law in 1975/6, no significant effect of the Dowry Prohibition Rules can be detected. For the remainder of India, the policy is estimated to have decreased dowry payments by around 3,500 rupees.

\section{$3 \quad$ Data and Summary Statistics}

\subsection{The Data and Sample}

This study employs data drawn from three rounds of the National Family Health Survey (NFHS) for India (NFHS-1, NFHS-2 and NFHS-3), a nationally representative survey of Indian households. The NFHS is part of the Demographic and Health Surveys series, which is conducted in about 70 low and middle income countries around the world. ${ }^{24}$ The questionnaires collect extensive information on health, nutrition and the complete birth histories of interviewed women. The NFHS-1 (IIPS 1994) was carried out in 1992 and 1993 and interviewed 89,777 ever-married women aged 13 to 49; the NFHS-2 (IIPS 1999) was conducted in 1998 and 1999 and interviewed 89,199 ever married women aged 15 to 49; finally the NFHS-3 (IIPS 2007b) was implemented in 2005 and 2006 and interviewed 124,385 women aged 15 to 49.

Individuals selected for estimation are women, who have experienced at least one birth and who had not yet reached the end of their reproductive years in 1985, the year of the

\footnotetext{
${ }^{23}$ The remaining covariates are defined as in equation 1 and include a religion specific linear time trend.

${ }^{24}$ The data are publicly available at www. measuredhs. com.
} 
Table 1: Effect of anti-dowry law on dowry payments

\begin{tabular}{|c|c|c|c|c|}
\hline \multirow[b]{3}{*}{ Sample } & (1) & $(2)$ & $(3)$ & $(4)$ \\
\hline & \multicolumn{4}{|c|}{ Dependent variable: Real dowry paid } \\
\hline & Amened & Unamended & Amened & Unamended \\
\hline Mean marriage 1975 - 1984 & 15,300 & 12,700 & 15,300 & 12,700 \\
\hline Hindu*Post1 & $\begin{array}{c}2317 \\
(3855)\end{array}$ & $\begin{array}{c}-1548^{* *} \\
(659)\end{array}$ & & \\
\hline Hindu*Post2 & & & $\begin{array}{l}1208 \\
(882)\end{array}$ & $\begin{array}{c}-3491^{* *} \\
(1418)\end{array}$ \\
\hline Religion specific trend & yes & yes & yes & yes \\
\hline Women & 1,581 & 8,393 & 1,581 & 8,393 \\
\hline R-Squared & 0.189 & 0.138 & 0.189 & 0.137 \\
\hline
\end{tabular}

Notes: Parameter estimates reported are from ordinary least squares model; dependent variable is the amount of dowry paid, all dowries are reported in 1985 prices; if no dowry is transferred, real dowries are coded as zero; Post1 is a dummy taking value 1 if woman $i$ married after 1985; Post2 is a dummy taking value 1 if woman $i$ was born after 1968; Hindu is a dummy taking value 1 if the religion of woman $i$ is Hinduism; covariates include woman's year of birth, education, partner's education, the number of household members, a dummy for whether the household owns land, household income and state dummies; all models control for religion-specific time trend; the sample consists of women born 1955 - 1975 married between 1975 and 1995; the sample in columns 1 and 3 refers to amended states (Bihar, Haryana, Himachal Pradesh and Punjab); the sample in columns 2 and 4 refers to unamended states, which are all states of India except the 4 aforementioned ones; standard errors are reported in parentheses and are clustered at the state level; ${ }^{* * *}$, **, and * indicate significance at the $1 \%, 5 \%$ and $10 \%$ levels.

introduction of the policy. The omission of childless women is unlikely to bias the results significantly, only 4 percent of women aged 35 to 40 in India have never experienced a birth (NFHS-3, 2007a). The final sample consists of 44,102 mothers, who were born between the years 1951 and 1968. Women in the sample show relatively low levels of education, around half of the individuals have completed primary school. The majority are Hindu (79 percent) with a minority of Muslim women (11 percent). Around 15 percent belong to a scheduled caste. Overall, the characteristics of women in the NFHS appear very similar to the ones of individuals drawn from the REDS (see section 2.2).

\subsection{Summary Statistics}

In the 1980s, fertility rates in India were high. According to the World Bank, the total fertility rate in 1985 was 4.3 children. Individuals in the NFHS sample have given birth to, on average, 4.5 children. The mean age at first birth is around 20 years. The median of the distribution lies at 4 children. Most women have between 2 and 5 children, the percentages 
of mothers with 2, 3, 4 and 5 children are 11,20,21 and 17 percent respectively.

The NFHS elicits retrospective questions on respondents' ideal number of children, sons and daughters. ${ }^{25}$ Individuals in the sample report an ideal number of 3.0 children, 1.6 sons and 1.1 daughters. ${ }^{26}$ Figure 4 shows the distribution of ideal children by gender. The left hand panel shows the ideal number of sons. The self-reported numbers suggest that the vast majority of mothers want either one or two sons. The right hand panel reports the ideal number of daughters. In contrast to before, most mothers prefer to have one daughter. Taken together these self-reported figures provide suggestive evidence that Indian mothers desire both, sons and daughters. However, they prefer at least as many boys as girls.

Figure 4: Ideal number of children

(a) Boys

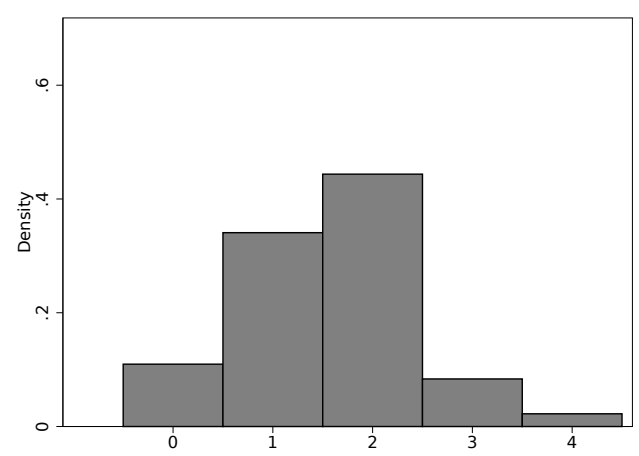

(b) Girls

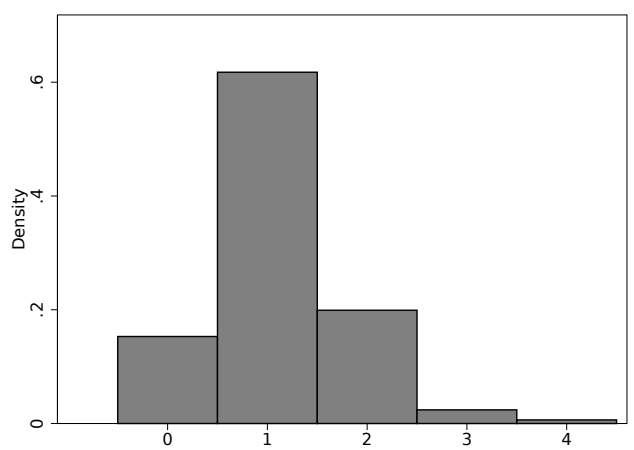

Notes: Figures show densities of self-reported ideal number of children; the question used is If you could choose exactly the number of children to have in your whole life, how many would that be? How many of these children would you like to be boys and how many girls? The sample consists of women born between 1951 and 1968 drawn from NFHS-1, NFHS-2 and NFHS-3.

First descriptive evidence also suggests that these attitudes are reflected in reproductive choices (as already highlighted by Mutharayappa et al., 1997; among others). Many parents keep on having children until they reach their ideal number of sons; 57 percent of women aged 40 or above stopped childbearing after having had a boy and only 43 percent after a girl. In fact, the birth of each girl increases fertility rates, even after conditioning on birth order. The conditional probability of childbirth for women with one daughter is 78 percent. This figure increases to 83 percent for families with two girls and 86 percent for families with three girls. ${ }^{27}$

\footnotetext{
${ }^{25}$ The relevant questions are If you could choose exactly the number of children to have in your whole life, how many would that be? and How many of these children would you like to be boys and how many girls?

${ }^{26}$ The number of ideal sons and daughters do not add up because in the second and third round of the NFHS women were also asked about their ideal number of children regardless of the sex.

${ }^{27}$ Note that the probabilities are calculated for exclusively female families. Thus, 73 percent refers to
} 


\section{Empirical Strategy}

The empirical specification investigates two questions: first, is there a significant association between the gender composition of siblings and their mother's fertility? Second, how does this association depend on the dowries parents expect to pay? To answer the first question, I model the probability that a woman gives birth in a given year as a function of her characteristics as well as the gender composition of her children. For this purpose, I use the retrospective birth histories drawn from the NFHS-1, NFHS-2 and NFHS-3 and construct a time series of 13 observations per woman, one for each year between 1980 and 1992. The dependent variable $y_{\text {ist }}$ takes the value 1 if woman $i$ living in state $s$ gives birth in year $t$

$$
y_{i s t}=X_{i s t} \beta+\alpha_{s}+\tau_{t}+\gamma_{g} G_{i}+\epsilon_{i s t}
$$

where $X_{i s t}$ consists of time-varying covariates for the mother ${ }^{28}$ and $\alpha_{s}$ and $\tau_{t}$ are state and year specific unobservable characteristics (so called state or year fixed effects). Finally, $G_{i}$ measures the gender composition of children. I select women with at least one child born before the sample period (i.e. 1979) and define $G_{i}=1$ if woman $i$ 's first child is female. The reference group consists of women, whose firstborn is male.

The gender composition of a woman's offspring can be measured in a number of ways. Possible definitions of $G_{i}$ include indicator variables for whether parents have more girls than boys, the ratio of girls to boys and the gender of the youngest child. In this particular context, however, only the gender of the first child (as used by Dahl and Moretti, 2008) is likely to be exogenous. There are two reasons for this assumption. First, any definition of $G_{i}$ using two or more children implicitly conditions on previous fertility choices made by parents. Using the gender of the first child, by contrast, is unlikely to suffer from this problem because the vast majority of Indian women bear children. Only 4 percent of women aged 35 to 40 in India have never experienced a birth (NFHS-3, 2007a).

Second, sex selective abortions allow parents to control the gender of their children. Foetal determination technologies, such as amniocentesis or ultrasound screening became available in India only from the 1980s onwards and most studies find declining sex ratios only from the late 1980s or early 1990s (see Bhaskar and Gupta, 2007; for an overview). The specification outlined above is unlikely to suffer from this bias since the youngest child used in the construction of $G_{i}$ was born in 1979. I carefully discuss the issue of sex selective abortions in sections 6.1 and 6.3 .

families with one child, 83 percent to families with two children and 86 percent to families with three children.

${ }^{28}$ These are education, religion, caste, marital status, age in year $t$, dummies for year of birth of mother $i$, a rural dummy and total number of children born in year $t$. 
A possible concern with the definition of $G_{i}$ is that the gender of the first child is not a strong predictor of the children's gender composition at any given time. I address this concern by regressing the proportion of children, who are female on maternal characteristics and the gender of her first child. The results in column 1 of table 6 show a strong association between the gender of the first child and the gender composition of all children. The firstborn being a girl shifts the gender composition by 26 percentage points.

In any case, I estimate equation 2 using alternative definitions of $G_{i}$ such as the gender of the youngest child, the ratio of daughters to sons and an indicator variable taking the value one if girls outnumber boys. If the results are robust across different definitions of $G_{i}$, one would expect to find similar results across the four different specifications.

To answer the second question, i.e. how the association between the sex mix of children and their mother's fertility depends on expected dowries, I exploit the introduction of the Dowry Prohibition Rules (1985). As the evidence provided in section 2.2 suggests, the decrease in dowry transfers resulting from this piece of legislation was up to $45 \%$ of household income. This marked decline, in turn, is likely to translate into an exogenous drop in the dowries parents expect to pay.

I evaluate the effect of the policy by testing whether the coefficient $\gamma_{g}$ changes as a result of the introduction of the Dowry Prohibition Rules (1985). For this purpose, I divide the sample period into the pre-policy (1980 to 1985) and post policy years (1986 to 1992) and compare $\gamma_{g}$ across both periods in a difference in differences framework. Note that the post period commences a year after the Dowry Prohibition Rules to account for the approximate duration of pregnancy. I estimate the following specification

$$
y_{i s t}=X_{i s t} \beta+\alpha_{s}+\tau_{t}+\gamma_{g} G_{i}+\gamma_{p} G_{i} P_{t}+\epsilon_{i s t}
$$

where $P_{t}=1$ for $t \geq 1986$; the remaining variables are defined as above. In this specification, $\gamma_{g}$ captures the effect of the firstborn being a girl (compared to a boy) on birth rates in the years before the introduction of the Dowry Prohibition Rules (between 1981 and 1985). The coefficient $\gamma_{p}$, by contrast, indicates how this effect changes after the introduction of the policy (between 1986 and 1992). We would expect $\gamma_{p}<0$ for the following intuitive reason. The institution of dowries incentivises son-stopping fertility behaviour. Many parents only stop having children once they reach their ideal number of boys. A decrease in expected dowries is likely weaken these incentives. I also estimate equation 3 using the alternative measures of $G_{i}$ described above. ${ }^{29}$

By comparing fertility behaviour over time, the specification in equation 3 differences out

\footnotetext{
${ }^{29}$ These are the gender of the youngest child, the ratio of daughters to sons and an indicator variable taking the value one if girls outnumber boys.
} 
time-invariant differences between women with a firstborn girl and women with a firstborn son. If there are time varying differences in fertility between these two groups, however, the coefficient $\gamma_{p}$ would erroneously attribute these to the Dowry Prohibition Rules. To address this concern, I take advantage of the fact that marital transfers for Muslims are exempt from the reform and compare fertility behaviour between Hindus and Muslims. For this purpose, I estimate equation 3 for both religions separately. To test whether the coefficients are statistically different between Hindus and Muslims, I pool all observations in a triple difference framework and estimate the following equation

$$
\begin{aligned}
y_{i s t} & =X_{i s t} \beta+\alpha_{s}+\tau_{t}+G_{i}+H_{i} \\
& +G_{i} H_{i}+G_{i} P_{t}+H_{i} P_{t}+\gamma_{h} G_{i} H_{i} P_{t}+\epsilon_{i s t}
\end{aligned}
$$

where $G_{i} H_{i} P_{t}$ is the triple interaction between woman $i$ 's first child being a girl $\left(G_{i}\right)$, her being Hindu $\left(H_{i}\right)$ and $t \geq 1986\left(P_{i}\right)$. This specification also allows for the pairwise interactions $H_{i} P_{t}, H_{i} G_{i}$ and $G_{i} P_{t}$; the remaining variables are defined as above.

Identification in the triple differences framework relies on the absence of time varying differences between women with firstborn sons and daughters, which affect Hindus and Muslims differently. One concern is that the parameter $\gamma_{h}$ reflects factors unrelated to the reform. The Hindu Succession Act, for instance, facilitated inheritance by daughters and may thus have affected the economic value of girls. This policy has been analysed recently (Deininger et al., 2013; Rosenblum, 2013b; Roy, 2011). ${ }^{30}$ Another concern is that because of cultural reasons Hindu women became more indifferent to the gender of their children over time.

To address these concerns, I exploit the exact timing of the implementation of the Dowry Prohibition Rules and analyse whether changes in fertility occur at the same time as the policy change. For this purpose, I re-estimate equation 3 substituting $P_{t} G_{i}$ with indicator variables for the years 1981 to 1992 as

$$
y_{i s t}=X_{i s t} \beta+\alpha_{s}+\tau_{t}+\gamma_{g} G_{i}+\sum_{\theta=1981}^{1992} \gamma_{\theta} G_{i} I_{\theta}+\epsilon_{i s t}
$$

where $I_{\theta}=1$ if $t=1981,1982, \ldots, 1992$; the remaining variables are defined as in equation 3. In this specification, the coefficients $\gamma_{\theta}$ denote the difference in $\gamma_{g}$ between year $\theta$ and the base year, 1980. I estimate equation 5 for Hindus and Muslims separately. If the Dowry Prohibition Rules affected fertility behaviour, one would expect a change in the fertility behaviour of Hindus only in the years immediately after the policy change. Reproductive

\footnotetext{
${ }^{30}$ Kerala changed the law in 1976, Andhra Pradesh in 1986, Tamil Nadu in 1989, Maharashtra and Karnataka in 1994.
} 
choices of Muslims, by contrast, should remain unaffected.

\section{Results}

\subsection{Sex Mix and Fertility Choices}

Table 2 presents the first set of results regarding the association between the gender composition of children and their mother's birth rates (based on equation 2). The sample consists of women born between 1951 and 1968, who have experienced at least one birth before the year 1979. The dependent variable takes the value 1 if woman $i$ living in state $s$ gives birth in year $t$. Before the introduction of the reform, on average 25 percent of women give birth every year.

Table 2: Gender of first child and birth rates

\begin{tabular}{|c|c|c|c|c|}
\hline \multirow{4}{*}{ Mean 1980 - 1985} & (1) & $(2)$ & $(3)$ & $(4)$ \\
\hline & \multicolumn{4}{|c|}{ Dependent variable: Birth indicator } \\
\hline & \multicolumn{4}{|c|}{0.253} \\
\hline & \multicolumn{3}{|c|}{ Parameter estimates } & Predicted \\
\hline Firstborn is female & $\begin{array}{l}0.021 * * * \\
(0.002)\end{array}$ & $\begin{array}{l}0.021 * * * \\
(0.002)\end{array}$ & $\begin{array}{l}0.022 * * * \\
(0.002)\end{array}$ & $19.6 \%$ \\
\hline Firstborn is male (base category) & & & & $17.4 \%$ \\
\hline Time dummies & no & yes & yes & \\
\hline Maternal covariates & no & no & yes & \\
\hline State dummies & yes & yes & yes & \\
\hline State specific trends & yes & yes & yes & \\
\hline Observations & 577,330 & 577,330 & 573,326 & \\
\hline Mothers & 44,410 & 44,410 & 44,102 & \\
\hline R-Squared & 0.056 & 0.057 & 0.08 & \\
\hline
\end{tabular}

Notes: Parameter estimates reported are from linear probability model; dependent variable takes value 1 if woman $i$ gives birth in year $t$; Firstborn is female is a dummy taking the value 1 if the firstborn child of woman $i$ is a girl; each woman contributes 13 observations, one for each year between 1980 and 1992; sample consists of women born between 1951 and 1968 with at least one child born before 1980 drawn from NFHS1, NFHS-2 and NFHS-3; mother level covariates include education, religion, caste, rural dummy, married dummy and dummies for birth cohort; regressions control for state-specific dummies and state-specific linear time trends; standard errors are reported in parentheses and are clustered at the state level; ${ }^{* *},{ }^{* *}$, and ${ }^{*}$ indicate significance at the $1 \%, 5 \%$ and $10 \%$ levels.

In the main specification, the gender composition of children is measured by the gender of her firstborn child. The parameter estimates suggest that the gender of the first child 
has a significant effect on women's fertility. Having a firstborn daughter (compared to a firstborn son) increases the probability of the woman giving birth by around 2 percentage points. Column 1 is the most basic specification, which only includes state dummies and state specific time trends. Column 2 adds time dummies and column 3 maternal characteristics. ${ }^{31}$ Column 4 uses the parameter estimates of column 3 to calculate the conditional probability of a further birth in the year 1985. Women with a firstborn girl give birth with a probability of $19.6 \%$. The corresponding figure for women with a firstborn boy is $17.4 \%$. These findings are in line with much of the demographic literature (Nag, 1991; Chaudhuri, 2012). To put these numbers into perspective, the difference induced by the gender of the firstborn child corresponds to a reduction of around 4 years in maternal education.

I also investigate whether the estimated association between the gender composition of children and their mother's fertility is robust to different definitions of the sex mix $\left(G_{i}\right)$. Table 3 reports the estimates of equation 2 using three alternative measures used by previous studies. Column 1 uses the gender of the most recent birth, column 3 the ratio of girls to boys in the family and column 5 a dummy for the woman having more girls than boys. The results are in line with the ones outlined in table 2. Across all definitions, gender compositions skewed towards girls increase birth rates.

\subsection{Dowries and Fertility Decisions}

Table 4 reports the results based on equation 3. This specification investigates the effect of the anti-dowry law on fertility choices. The results shown in column 1 suggest that, before the introduction of the Dowry Prohibition Rules, women with a firstborn daughter are 2.5 percentage points more likely to experience a birth compared to women with a firstborn son. The anti-dowry law of 1985 decreased this gap in birth rates by 0.6 percentage points. As a next step, I estimate equation 3 for Hindus and Muslims separately. The results in columns 2 and 3 suggest that, before the policy, the gender of the first child affects reproductive behaviour of Hindus but not of Muslims. Hindus experience a significant decrease in $\gamma_{p}$ whereas the same parameter remains unaffected for Muslims. Column 4 reports the estimate based on equation 4 , which pools all women and estimates a triple difference framework. The parameter estimate suggests that the reform decreased $\gamma_{g}$ by 1.3 percentage points.

The parameter estimates in equation 4 can be used approximate the effect of the Dowry Prohibition Rules on lifetime fertility. For this purpose, I first estimate the difference in lifetime fertility between women with a firstborn boy and firstborn girl. Estimates based on women, who finished their childbearing years before the introduction of the Dowry Prohibi-

\footnotetext{
${ }^{31}$ These influce education, religion, caste, marital status, age in year $t$, dummies for year of birth, a rural dummy and total number of children born in year $t$.
} 
Table 3: Alternative definitions of children's gender composition

\begin{tabular}{|c|c|c|c|c|c|c|}
\hline & $(1)$ & $(2)$ & $(3)$ & $(4)$ & $(5)$ & $(6)$ \\
\hline & \multicolumn{6}{|c|}{ Dependent variable: Birth indicator } \\
\hline & \multicolumn{6}{|c|}{ Measurement of $G_{i}$} \\
\hline & \multicolumn{2}{|c|}{ Youngest child is female } & \multicolumn{2}{|c|}{ Ratio of girls to boys } & \multicolumn{2}{|c|}{ More girls than boys } \\
\hline$G_{i}$ & $\begin{array}{l}0.019 * * * \\
(0.001)\end{array}$ & $\begin{array}{l}0.023 * * * \\
(0.002)\end{array}$ & $\begin{array}{l}0.042 * * * \\
(0.001)\end{array}$ & $\begin{array}{l}0.069 * * * \\
(0.002)\end{array}$ & $\begin{array}{l}0.046 * * * \\
(0.004)\end{array}$ & $\begin{array}{l}0.050 * * * \\
(0.004)\end{array}$ \\
\hline$G_{i} *$ Post & & $\begin{array}{c}-0.007 * * * \\
(0.003)\end{array}$ & & $\begin{array}{c}-0.042 * * * \\
(0.003)\end{array}$ & & $\begin{array}{c}-0.008 * * \\
(0.003)\end{array}$ \\
\hline State specific trends & yes & yes & yes & yes & yes & yes \\
\hline Observations & 573,281 & 573,281 & 519,655 & 519,655 & 573,326 & 573,326 \\
\hline Mothers & 44,098 & 44,098 & 39,973 & 39,973 & 44,102 & 44,102 \\
\hline R-Squared & 0.079 & 0.079 & 0.102 & 0.105 & 0.082 & 0.082 \\
\hline
\end{tabular}

Notes: Parameter estimates reported are from linear probability model; dependent variable takes value 1 if woman $i$ gives birth in year $t$; Post is a dummy taking value 1 if $t \geq 1986$; Youngest child is female is a dummy variable taking the value 1 if the youngest child born before year $t$ is a girl; Ratio of girls to boys is the total number of girls born by year $t$ divided by the total number of boys; More girls than boys is a dummy variable taking the value 1 if in year $t$ the total number of girls exceeds the total number of boys; each woman contributes 13 observations, one for each year between 1980 and 1992; sample consists of women born between 1951 and 1968 with at least one child born before 1980 drawn from NFHS-1, NFHS-2 and NFHS-3; mother level covariates include education, religion, caste, rural dummy, married dummy and dummies for birth cohort; regressions control for state-specific dummies and state-specific linear time trends; standard errors are reported in parentheses and are clustered at the state level; ${ }^{* * *}, * *$, and $*$ indicate significance at the $1 \%, 5 \%$ and $10 \%$ levels.

tion Rules, indicate that women with a firstborn girl have, on average, 0.43 children more (than women with a firstborn boy). According to these estimates, the anti-dowry law decreases lifetime fertility by 0.11 children. For women directly affected by the policy, the effect is smaller, 0.06 children. These calculations rest on a number of assumptions, for instance that the son preferring stopping rules are relatively constant over time and can thus only be seen as suggestive.

The results in table 3 show that the effect of the Dowry Prohibition Rules is robust to various definitions of the gender composition of children. The coefficients on the interactions between the gender composition, $G_{i}$, and the post dummy, $P_{t}$, in columns 2,4 and 6 are negative and statistically significant.

The event study estimates reported in figure 5 show that the change in behaviour occurred only for Hindu women and only in the years after the Dowry Prohibition Rules. Panels a and b depict the point estimates (solid line) along with their 95\% confidence intervals (dashed line) based on equation 5 for Hindus and Muslims respectively. Panel a shows a marked 
Table 4: Effect of anti-dowry law on birth rates

\begin{tabular}{|c|c|c|c|c|c|c|}
\hline \multirow[b]{3}{*}{ Sample } & $(1)$ & $(2)$ & $(3)$ & $(4)$ & $(5)$ & $(6)$ \\
\hline & \multicolumn{6}{|c|}{ Dependent variable: Birth indicator } \\
\hline & India & Hindu & Muslim & India & Amended & Unamended \\
\hline Mean (1981 - 1985) & 0.253 & 0.247 & 0.297 & 0.253 & 0.260 & 0.251 \\
\hline Firstborn is female & $\begin{array}{l}0.025 * * * \\
(0.003)\end{array}$ & $\begin{array}{l}0.028 * * * \\
(0.003)\end{array}$ & $\begin{array}{c}0.007 \\
(0.006)\end{array}$ & $\begin{array}{c}0.006 \\
(0.006)\end{array}$ & $\begin{array}{l}0.044 * * \\
(0.010)\end{array}$ & $\begin{array}{r}-0.003 \\
(0.006)\end{array}$ \\
\hline Firstborn is female*Post & $\begin{array}{c}-0.006 * * * \\
(0.002)\end{array}$ & $\begin{array}{c}-0.008 * * * \\
(0.002)\end{array}$ & $\begin{array}{c}0.005 \\
(0.005)\end{array}$ & & & \\
\hline Firstborn is female*Post*Hindu & & & & $\begin{array}{c}-0.013 * * \\
(0.006)\end{array}$ & $\begin{array}{c}0.012 \\
(0.018)\end{array}$ & $\begin{array}{c}-0.020 * * * \\
(0.007)\end{array}$ \\
\hline State specific trends & yes & yes & yes & yes & yes & yes \\
\hline Observations & 573,326 & 507,312 & 66,014 & 573,326 & 108,563 & 464,763 \\
\hline Mothers & 44,102 & 39,024 & 5,078 & 44,102 & 8,351 & 37,751 \\
\hline R-Squared & 0.080 & 0.083 & 0.061 & 0.082 & 0.087 & 0.081 \\
\hline
\end{tabular}

Notes: Parameter estimates reported are from linear probability model; dependent variable takes value 1 if woman $i$ gives birth in year $t$; Firstborn is female is a dummy taking the value 1 if the firstborn child of woman $i$ is a girl; Post is a dummy taking value 1 if $t \geq 1986$; Hindu is a dummy taking value 1 if the religion of woman $i$ is Hinduism; each woman contributes 13 observations, one for each year between 1980 and 1992; sample consists of women born between 1951 and 1968 with at least one child born before 1980 drawn from NFHS-1, NFHS-2 and NFHS-3; mother level covariates include education, religion, caste, rural dummy, married dummy and dummies for birth cohort; regressions control for state-specific dummies and state-specific linear time trends; the sample in columns 1 and 4 refers to the whole of India, the sample in column 2 to Hindu women, the sample in column 3 to Muslim women, the sample in column 4 to amended states (Bihar, Haryana, Himachal Pradesh, Jammu and Kashmir and Punjab), the sample in column 5 to unamended states, which are all states of India except the 5 aforementioned states; standard errors are reported in parentheses and are clustered at the state level; ${ }^{* * *},{ }^{* *}$, and $*$ indicate significance at the $1 \%$, $5 \%$ and $10 \%$ levels.

change in Hindus' fertility behaviour. For this group, $\gamma_{\theta}$ is relatively constant in the years before the policy. In the year of the policy (shown by the solid line), there is no change. After accounting for the duration of pregnancy (shown by the dashed vertical line), however, the estimates decline. The coefficient $\gamma_{\theta}$ for the Muslim sample, by contrast, shows no decrease after the policy. For this group, the estimates oscillate around zero.

It is interesting to note that a decrease in expected dowries must not necessarily translate into a decrease son biased fertility stopping rules. With a lower dowry, parents are able to space daughters more closely together without either binding liquidity constraints or increasing marriage search pressure. Consequently, after the birth of a girl, parents may wait less to continue child bearing thus strengthening the positive correlation between the number of daughters and their parents' fertility. This mechanism is discussed by Vogl (2016). 
Figure 5: Gender of first child and yearly birth rates (1981 to 1992)

(a) Hindus

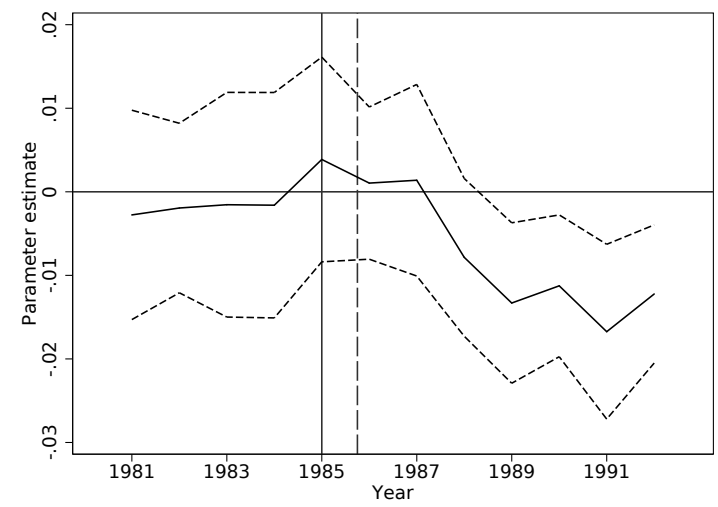

(b) Muslims

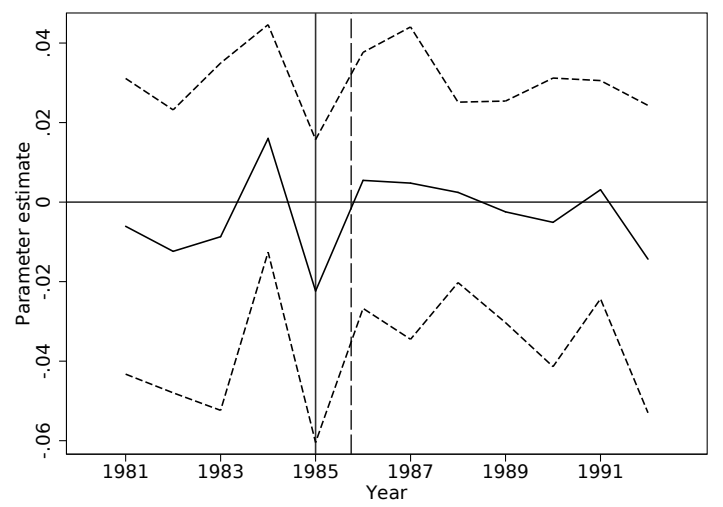

Notes: Figure shows effect of the Dowry Prohibition Rules by year $t$; Parameter estimates reported are from linear probability model; dependent variable takes value 1 if woman $i$ gives birth in year $t$; solid lines refer to coefficient estimates on interactions between Firstborn is female, a dummy taking the value 1 if the firstborn child of woman $i$ is a girl, and $I_{\theta}$, a vector of dummies taking the value 1 if $\theta=t$; the base year is 1980; $95 \%$ confidence intervals are shown as dashed lines; sample consists of women born between 1951 and 1968 with at least one child born before 1980 drawn from NFHS-1, NFHS-2 and NFHS-3; mother level covariates include education, religion, caste, rural dummy, married dummy and dummies for birth cohort; regressions control for state-specific dummies and state-specific linear time trends; panel a: the sample refers to Hindu women, panel b: the sample refers to Muslim women, standard errors are clustered at the state level.

The fact that, in this instance, lower dowries lead to a decrease in son biased stopping rules (as outlined here) suggests that the aforementioned mechanism is dominated by the income effect resulting from lower expected future payments.

\subsection{Treatment Heterogeneity}

This section employs the specification based on equation 4 to investigate how the effect of the anti-dowry law varies by the characteristics of the mother.

Columns 1 and 2 of table 5 distinguish between patri- and matrilineal states. ${ }^{32}$ Patrilineal states are characterised by higher preferences for sons and higher dowry transfers. One would, thus, expect to find a stronger impact in these states. The pre-period means show that patrilineal states have much higher fertility rates, again a fact that is well known. The parameter estimates, further, show that the impact of the anti-dowry law was much more pronounced in patrilineal states. For this area, the decrease is of 3.6 percentage points whereas in matrilineal states the effect is only 0.2 percentage points. Further, in these latter

\footnotetext{
${ }^{32}$ Patrilineal states are Rajasthan, Gujarat, Orissa, Madhya Pradesh and Jharkahand. Matrilineal states are Kerala and Meghalaya.
} 
states, the coefficient is not statistically different from zero.

Table 5: Heterogenous effect of anti-dowry law on birth rates

\begin{tabular}{|c|c|c|c|c|c|c|c|c|c|}
\hline & (1) & (2) & (3) & (4) & (5) & (6) & (7) & (8) & (9) \\
\hline & \multicolumn{9}{|c|}{ Dependent variable: Birth indicator } \\
\hline & $\begin{array}{c}\text { Matrilineal } \\
\text { States }\end{array}$ & $\begin{array}{c}\text { Patrilineal } \\
\text { States }\end{array}$ & $\begin{array}{c}\text { No Primary } \\
\text { education }\end{array}$ & $\begin{array}{l}\text { Primary } \\
\text { education }\end{array}$ & $\begin{array}{c}\text { Above av. } \\
\text { age at } \\
\text { marriage }\end{array}$ & $\begin{array}{l}\text { Below av. } \\
\text { age at } \\
\text { marriage }\end{array}$ & $\begin{array}{c}\text { Born } \\
1951-56\end{array}$ & $\begin{array}{c}\text { Born } \\
1957-62\end{array}$ & $\begin{array}{c}\text { Born } \\
1963-68\end{array}$ \\
\hline Mean 1980-1985 & 0.199 & 0.267 & 0.273 & 0.216 & 0.251 & 0.257 & 0.203 & 0.296 & 0.339 \\
\hline Firstborn is female & $\begin{array}{l}-0.001 \\
(0.005)\end{array}$ & $\begin{array}{c}0.004 \\
(0.010)\end{array}$ & $\begin{array}{c}0.006 \\
(0.008)\end{array}$ & $\begin{array}{c}0.006 \\
(0.009)\end{array}$ & $\begin{array}{c}0.009 \\
(0.007)\end{array}$ & $\begin{array}{c}0.000 \\
(0.009)\end{array}$ & $\begin{array}{c}0.004 \\
(0.009)\end{array}$ & $\begin{array}{c}0.009 \\
(0.010)\end{array}$ & $\begin{array}{c}-0.010 \\
(0.018)\end{array}$ \\
\hline Firstborn is female*Hindu*Post & $\begin{array}{l}-0.002 \\
(0.009)\end{array}$ & $\begin{array}{c}-0.036 * * * \\
(0.006)\end{array}$ & $\begin{array}{c}-0.010 \\
(0.008)\end{array}$ & $\begin{array}{c}-0.018 * \\
(0.010)\end{array}$ & $\begin{array}{c}-0.018 * * \\
(0.007)\end{array}$ & $\begin{array}{c}-0.003 \\
(0.014)\end{array}$ & $\begin{array}{c}-0.017 \\
(0.011)\end{array}$ & $\begin{array}{c}-0.006 \\
(0.009)\end{array}$ & $\begin{array}{c}-0.035 \\
(0.023)\end{array}$ \\
\hline State specific trends & yes & yes & yes & yes & yes & yes & yes & yes & yes \\
\hline $\begin{array}{l}\text { Observations } \\
\text { Mothers }\end{array}$ & 27,677 & 132,795 & 368,914 & 204,412 & 408,070 & 165,256 & 286,494 & 259,441 & 27,391 \\
\hline R-Squared & 0.079 & 0.086 & 0.071 & 0.102 & 0.085 & 0.075 & 0.073 & 0.075 & 0.063 \\
\hline
\end{tabular}

Notes: Parameter estimates reported are from linear probability model; dependent variable takes value 1 if woman $i$ gives birth in year $t$; Firstborn is female is a dummy taking the value 1 if the firstborn child of woman $i$ is a girl; Post is a dummy taking value 1 if $t \geq 1986$; Hindu is a dummy taking value 1 if the religion of woman $i$ is Hinduism; each woman contributes 13 observations, one for each year between 1980 and 1992; sample consists of women born between 1951 and 1968 with at least one child born before 1980 drawn from NFHS-1, NFHS-2 and NFHS-3; mother level covariates include education, religion, caste, rural dummy, married dummy and dummies for birth cohort; regressions control for state-specific dummies and state-specific linear time trends; standard errors are reported in parentheses and are clustered at the state level; Matrilineal states in column 1 refers to Kerala and Meghalaya; Patrilineal states in column 2 refers to Rajasthan, Gujarat, Orissa, Madhya Pradesh and Jharkahand; Above average age at marriage in column 5 refers to ; Below average age at marriage in column 6 refers to ; ${ }^{* *},{ }^{* *}$, and ${ }^{*}$ indicate significance at the $1 \%, 5 \%$ and $10 \%$ levels.

The results reported in columns 3 and 4 suggest that the impact of the Dowry Prohibition Rules was stronger for more educated women. The effect for mothers with primary education is 1.8 percentage points, the corresponding estimate for women without primary education is one percentage point. One possible explanation for this finding is that women with higher levels of education are likely to have higher levels of autonomy. The resulting improved agency is likely to enable these individuals to respond more effectively to the new circumstances by affecting decisions taken by the household as a whole. Columns 5 and 6 approximate a woman's autonomy by her age at marriage (Abadian, 1996). The results confirm that more autonomous women responded more strongly to the Dowry Prohibition Rules. Finally, the results in columns 7 to 9 show that the effect of the anti-dowry law is relatively stable across different age groups. 


\section{Identification}

The causal interpretation of the results presented in section 5 relies on two assumptions. First, the gender of the firstborn child is randomly assigned. Second, after accounting for unobservable state and time characteristics, there are no gender specific time varying factors, which affect Hindus and Muslims differently and which occur simultaneously with the Dowry Prohibition Rules. This section assesses the plausibility of these two assumptions in the present context.

\subsection{Random Assignment of Firstborn's Gender}

The random assignment of the first child's gender rests on the assumption that parents do not sex selectively abort at birth order one. Numerous studies have found that in India sex ratios of firstborn children lie within normal limits (Rosenblum, 2013a; Poertner, 2010; Retherford and Roy, 2003). Bhalotra and Cochrane (2010) point out that in India ultrasound technology became available only from the middle of the 1980s onwards. The authors also argue that most of the take-up took place from the early 1990s onwards. Because the youngest child used to construct the variable $G_{i}$ was born in 1979, its gender is unlikely to have been affected by sex selective abortions.

To investigate this claim further, I regress the gender of firstborn children on their mother's characteristics using the following specification

$$
w_{j s t}=X_{j s t} \beta+\alpha_{s}+\tau_{t}+\epsilon_{j s t}
$$

where $w_{j s t}=1$ if child $j$ born in state $s$ in year $t$ is female, $X_{j s t}$ are mother specific characteristics and $\alpha_{s}$ and $\tau_{t}$ are fixed effects for state of residence and the child's year of birth. Columns 2 and 3 in table 6 compare the characteristics of mothers with a firstborn girl with those of mothers with a firstborn boy. The characteristics appear very balanced across the two samples with only minor differences across all means.

Column 4 reports the parameter estimates of equation 6 . Overall, maternal characteristics do not appear to influence the gender of her child. The parameter for the constant provides further evidence for the exogeneity of the child's gender. The estimate of 0.482 is within the limits of the natural rate, which has been documented to lie between 48.2 and 48.8. Finally, the low $R$ squared suggests that maternal characteristics can explain only very little of the variation in sex ratios at birth. This is a further indication for the random allocation of the gender of the firstborn. 
Table 6: Determinants of gender of children

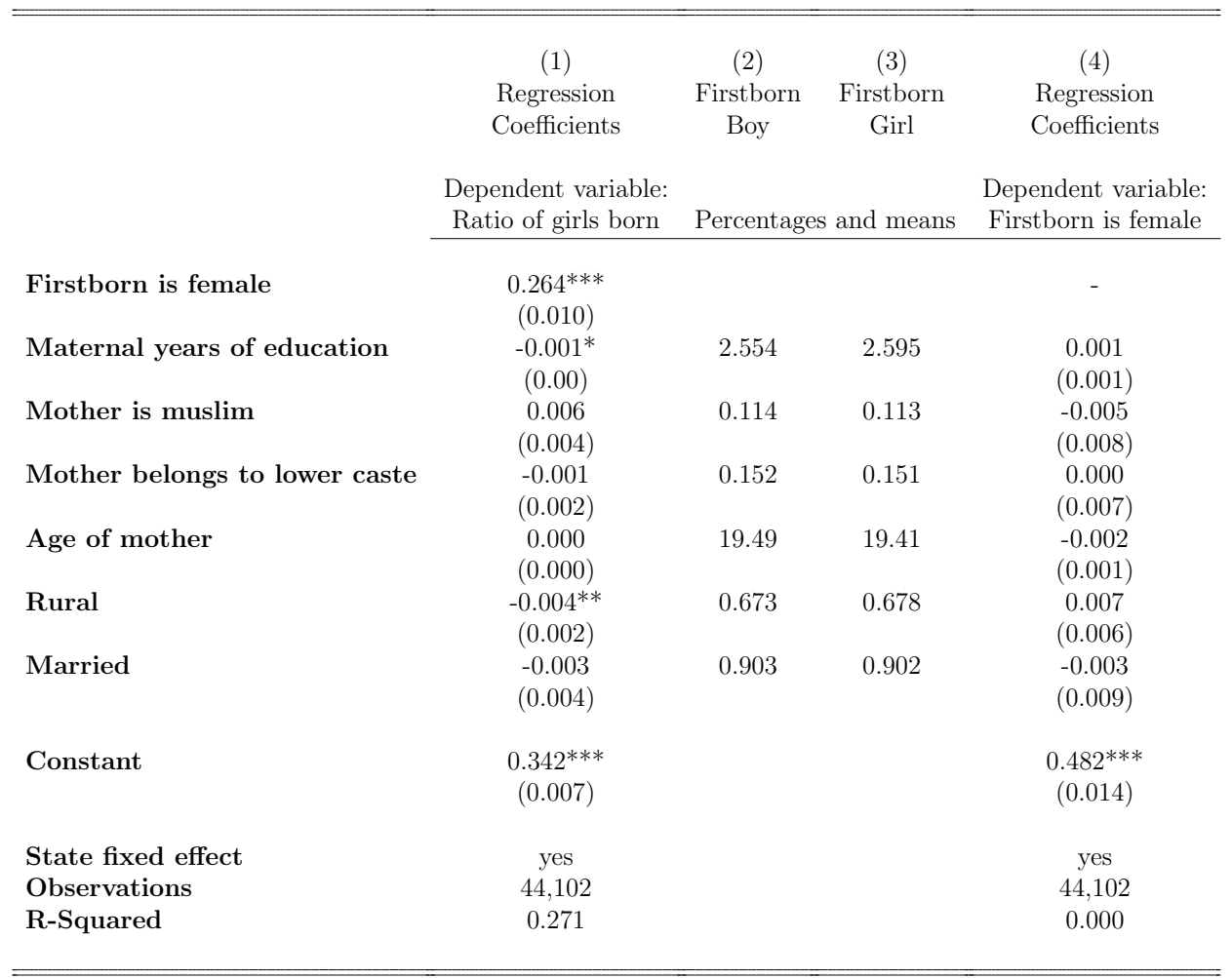

Notes: Parameter estimates reported are from ordinary least squares model; dependent variable in column 1 is girls as proportion of all children born; dependent variable in column 4 takes value 1 if firstborn child is female; Firstborn is female is a dummy taking the value 1 if the firstborn child of woman $i$ is a girl; covariates include Maternal years of education the total number of years mother spent in school, Mother is Muslim an indicator variable taking the value 1 if mother's religion is Islam, Mother belongs to lower caste an indicator variable taking value 1 if mother's caste is defined as "lower", Age of mother in years, Rural a dummy taking the value 1 if women resides in rural area and Married a dummy taking the value 1 if woman is currently married, sample consists of women born between 1951 and 1968 drawn from NFHS-1, NFHS-2 and NFHS-3; standard errors are reported in parentheses and are clustered at the state level; ${ }^{* *},{ }^{* *}$, and * indicate significance at the $1 \%, 5 \%$ and $10 \%$ levels.

\subsection{Confounding factors}

This section investigates the relative importance of alternative explanations for differences in the reproductive behaviour of Hindus and Muslims. One concern is that other policies implemented by the central government around the year 1985 may have changed the behaviour of Hindu women in particular. India implemented numerous nationwide reforms to liberalise its economy. The changes were designed to encourage commodity exports, deregulate the industrial sector and rationalise the tax system (see De Jong, 2003; for an overview). These policies had a pronounced impact on India's economy. Exports grew by around $15 \%$ and GDP growth average around 5.6\% (Virmani, 2004a) and productivity increased significantly, especially in the manufacturing sector (Virmani, 2004b). In many instances, women were 
in a particularly advantageous position to exploit the new opportunities brought about by these policies (see Munshi and Rosenzweig, 2006, for an example), especially if they were Hindus. If these changing circumstances increased the value of Hindu daughters and thus influenced parental fertility choices, their effect would erroneously be attributed to the Dowry Prohibition Rules.

I address this concern by exploiting inter-state variation in the application of dowry laws brought about by state-specific legislations, which tightened anti-dowry provisions prior to the introduction of the Dowry Prohibition Rules. For this purpose, I compare fertility behaviour across states that amended the Dowry Prohibition Act of 1961 in the years 1975/6 and the remainder of the country. ${ }^{33}$ As explained in section 2.2, the impact of the reform was significantly stronger in unamended states.

I investigate the hypothesis that the impact of the Dowry Prohibition Rules varied between amended and unamended states in two ways. First, I estimate the triple difference framework outlined in equation 4 for each set of states separately. Columns 5 and 6 of table 4 report the estimates for amended and unamended states respectively. The parameter estimates suggest that the impact of the Dowry Prohibition Rules in amendment states was negligible. The parameter estimate is of 0.012 percentage and not statistically significantly different from zero. By contrast, the corresponding estimate for unamended states is -0.02 , which is statistically significantly different from zero.

In a second step, I use an event study approach to compare fertility changes over time in both areas. For this purpose, I estimate the triple differences specification outlined in equation 4 for each year between 1981 and 1992 individually. In practice, I substitute the post dummy $\left(P_{t}\right)$ with indicator variables for the years 1981 to 1992 . The resulting parameter estimates denote the differences in the effect of the firstborn's gender on fertility between Hindus and Muslims for each year. I estimate this model for amended and unamended states separately. If the aforementioned state amendments led to a decrease in the impact of the Dowry Prohibition Rules, one would expect the parameter estimates to become negative in the years after 1986 in unamended states. In amended states, by contrast, the estimates would remain constant over time.

One advantage of the event study approach is that it makes it possible to test whether reproductive behaviour changes at any point prior to the year 1985. Such a test is important for the comparison between amended and unamended states because it addresses the concern of diverging time trends between the two areas. It is possible, for instance, that the introduction of the state amendments in 1975/76 was brought about by unobservable preferences

\footnotetext{
${ }^{33}$ Recall that these states are Bihar, Haryana, Himachal Pradesh, Jammu and Kashmir and Punjab. See section 2.2 for more details.
} 
that may also affect fertility choices. In such a case, fertility behaviour would already differ between amended and unamended states before the introduction of the Dowry Prohibition Rules. Panels a and b of figure 6 show two interesting patterns. First, changes in fertility behaviour in unamended states occur only from 1986 onwards (panel a). In amended states, by contrast, no distinctive change is discernible. Second, in the years before the Dowry Prohibition Rules the time trends in amended and unamended states are relatively parallel. This finding speaks against the fact that unobserved factors may be driving both the introduction of state amendments and changes in reproductive behaviour.

Figure 6: Gender of first child and yearly birth rates - triple differences (1981 to 1992)

(a) Unamended states

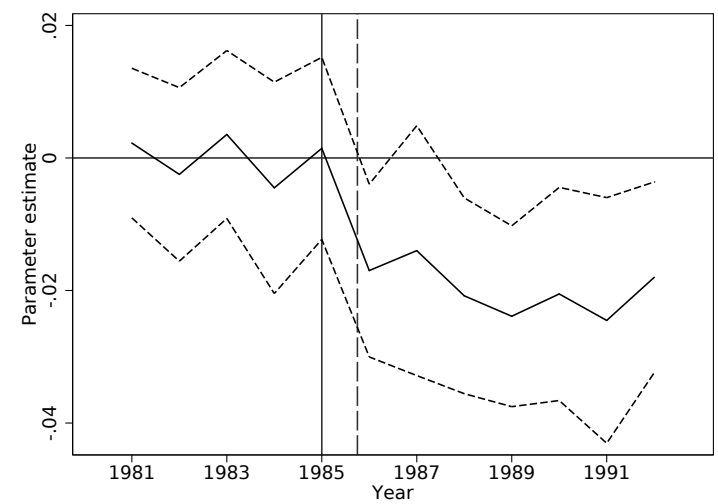

(b) Amended states

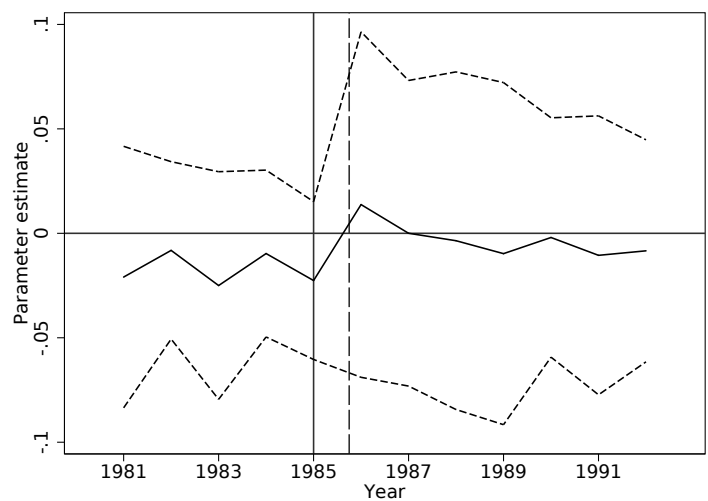

Notes: Figure shows effect of the Dowry Prohibition Rules by year $t$; Parameter estimates reported are from linear probability model; dependent variable takes value 1 if woman $i$ gives birth in year $t$; solid lines refer to coefficient estimates on triple interactions between Firstborn is female, a dummy taking the value 1 if the firstborn child of woman $i$ is a girl, Hindu, a dummy taking value 1 if the religion of woman $i$ is Hinduism, and $I_{\theta}$, a vector of dummies taking the value 1 if $\theta=t$; the base year is 1980; $95 \%$ confidence intervals are shown as dashed lines; standard errors are clustered at state level; sample consists of women born between 1951 and 1968 with at least one child born before 1980 drawn from NFHS-1, 2 and 3; mother level covariates include education, religion, caste, rural dummy, married dummy and dummies for birth cohort; regressions control for state-specific dummies and state-specific linear time trends; panel a: sample consists of unamended states, panel b: sample consists of amended states (Bihar, Haryana, Himachal Pradesh, Punjab and Jammu and Kashmir).

\subsection{Sex Selective Abortions}

This section investigates the effect of the anti-dowry law on sex ratios at birth. A possible concern with the identification strategy outlined in section 4 is that parents do not respond to the change in expected dowries by changing their fertility behaviour. Instead, they attempt to affect the gender of their children at birth. In fact, Bhalotra and Cochrane (2010) point out that families with a firstborn daughter have an incentive to abort female foetuses. 
The event study estimates shown in figure 5 provide first evidence that parents did not respond to the reform via sex selective abortions. As discussed, fertility behaviour changes in the year 1986, at which point sex selective technologies were not widespread in India. It is, thus, unlikely that parents had the technology to influence the gender of their children at birth.

To investigate this claim further, I model the probability of the birth of a girl as a function of maternal characteristics and the introduction of the anti-dowry law. In essence, I estimate a triple differences framework as the one outlined in equation 4 . In this instance, however, the dependent variable $w_{i s t}$ takes the value 1 if woman $i$ residing in state $s$ gives birth to a girl in year $t$. If individuals responded to the Dowry Prohibition Rules by aborting female foetuses, one would expect the policy to have a significant impact on the probability of female births.

Overall, the results suggest that the introduction of the Dowry Prohibition Rules did not affect sex ratios at birth (see table 7 ). Column 1 only includes state dummies as explanatory variables, column 2 adds time dummies and column 3 maternal characteristics. Throughout these different specifications, the parameter estimates for $\gamma_{p}$ remain small in size and not statistically different from zero.

As a further check, I analyse the sex ratios at birth for a woman's complete birth history. For this purpose, I construct a dataset following the methodology outlined by Bhalotra and Cochrane (2010). In this specification, I model $w_{i j t}$, which is the probability that a birth of order $j$ born in year $t$ to mother $i$ is female. The model only considers children of birth order 2 or higher. In contrast to the approach taken so far where each woman contributes 13 observations, one for each year between 1980 and 1992, in this framework each woman contributes $N-1$ observations where $N$ is the number of children ever born to a woman. Women in the sample gave birth to 216,909 children between the years 1960 and 2005. For this sample I estimate the following specification

$$
\begin{aligned}
w_{i j t} & =X_{i j t} \beta+\alpha_{s}+\tau_{t}+G_{i}+H_{i} \\
& +G_{i} H_{i}+G_{i} P_{t}+H_{i} P_{t}+\gamma_{h} G_{i} H_{i} P_{t}+\epsilon_{i s t}
\end{aligned}
$$

where $w_{i j t}$ takes the value 1 if a birth of order $j$ born in year $t$ to mother $i$ is female, $G_{i}=1$ if the firstborn child to woman $i$ is female, $H_{i}=1$ if woman $i$ is Hindu and $P_{t}=1$ if child $j$ is born after the year 1985. Akin to before, the effect of the Dowry Prohibition Rules is captured by the triple interaction $G_{i} H_{i} P_{t}$. The advantage of this framework is that it models all children ever born to women.

The parameter estimates based on equation 7 are reported in columns 1 and 2 of table 
Table 7: Effect of anti-dowry law on sex ratios at birth

\begin{tabular}{|c|c|c|c|c|c|c|}
\hline & (1) & $(2)$ & $(3)$ & $(4)$ & $(5)$ & $(6)$ \\
\hline & \multicolumn{6}{|c|}{ Dependent variable: Female birth indicator } \\
\hline Mean 1980 - 1985 & \multicolumn{6}{|c|}{0.121} \\
\hline Firstborn is female & $\begin{array}{c}0.001 \\
(0.004)\end{array}$ & $\begin{array}{c}0.001 \\
(0.004)\end{array}$ & $\begin{array}{c}-0.000 \\
(0.004)\end{array}$ & $\begin{array}{c}-0.001 \\
(0.005)\end{array}$ & $\begin{array}{c}-0.001 \\
(0.005)\end{array}$ & $\begin{array}{c}-0.002 \\
(0.005)\end{array}$ \\
\hline Firstborn is female*Hindu*Post & $\begin{array}{r}-0.006 \\
(0.005)\end{array}$ & $\begin{array}{r}-0.006 \\
(0.005)\end{array}$ & $\begin{array}{r}-0.006 \\
(0.005)\end{array}$ & & & \\
\hline Firstborn is female*Hindu* $1(1984-85)$ & & & & $\begin{array}{r}-0.003 \\
(0.007)\end{array}$ & $\begin{array}{r}-0.003 \\
(0.007)\end{array}$ & $\begin{array}{r}-0.003 \\
(0.007)\end{array}$ \\
\hline Firstborn is female*Hindu* $1(1986-92)$ & & & & $\begin{array}{r}-0.007 \\
(0.007)\end{array}$ & $\begin{array}{r}-0.007 \\
(0.007)\end{array}$ & $\begin{array}{r}-0.007 \\
(0.007)\end{array}$ \\
\hline Time dummies & no & yes & yes & no & yes & yes \\
\hline Maternal covariates & no & no & yes & no & no & yes \\
\hline State specific trends & yes & yes & yes & yes & yes & yes \\
\hline Observations & 577,330 & 577,330 & 573,326 & 577,330 & 577,330 & 573,326 \\
\hline Mothers & 44,410 & 44,410 & 44,102 & 44,410 & 44,410 & 44,102 \\
\hline R-Squared & 0.025 & 0.026 & 0.035 & 0.026 & 0.026 & 0.035 \\
\hline
\end{tabular}

Notes: Parameter estimates reported are from linear probability model; dependent variable takes value 1 if woman $i$ gives birth in year $t$ to a girl; Firstborn is female is a dummy taking the value 1 if the firstborn child of woman $i$ is a girl; Post is a dummy taking value 1 if $t \geq 1986$; 1(1984-85) is a dummy taking value 1 if $1984 \geq t \leq 1985$; 1 (1986-92) is a dummy taking value 1 if $1986 \geq t \leq 1992$; Hindu is a dummy taking value 1 if the religion of woman $i$ is Hinduism; each woman contributes 13 observations, one for each year between 1980 and 1992; sample consists of women born between 1951 and 1968 with at least one child born before 1980 drawn from NFHS-1, NFHS-2 and NFHS-3; mother level covariates include education, religion, caste, rural dummy, married dummy and dummies for birth cohort; regressions control for state-specific dummies and state-specific linear time trends; standard errors are reported in parentheses and are clustered at the state level; ***,**, and * indicate significance at the $1 \%, 5 \%$ and $10 \%$ levels.

8. The figures show that, even using this methodology, the Dowry Prohibition Rules had no significant impact of sex ratios at birth. Column 1 reports the results for the triple interaction between the Hindu dummy, a dummy for the firstborn in the family being female and a dummy for whether child $i$ is born after 1985. In column 2 I follow the specification by Bhalotra and Cochrane (2010) and define two post dummies, one for child $i$ being born between 1986 and 1994 (post1) and one he or she being born between 1995 and 2005 (post2). In both specifications, the point estimates are small in magnitude and not statistically different from zero. 
Table 8: Effect of anti-dowry law - alternative specifications

\begin{tabular}{|c|c|c|c|c|c|c|}
\hline \multirow[b]{4}{*}{ Sample } & $(1)$ & $(2)$ & $(3)$ & $(4)$ & $(5)$ & $(6)$ \\
\hline & \multicolumn{6}{|c|}{ Dependent variable: } \\
\hline & \multicolumn{2}{|c|}{ Female birth indicator } & \multicolumn{4}{|c|}{ Birth indicator } \\
\hline & India & India & India & Hindus & Muslims & India \\
\hline Mean 1980 - 1985 & \multicolumn{2}{|c|}{0.478} & 0.833 & 0.825 & 0.888 & 0.833 \\
\hline Firstborn is female & $\begin{array}{r}-0.002 \\
(0.009)\end{array}$ & $\begin{array}{r}-0.002 \\
(0.009)\end{array}$ & $\begin{array}{l}0.039 * * * \\
(0.005)\end{array}$ & $\begin{array}{l}0.044 * * * \\
(0.005)\end{array}$ & $\begin{array}{c}0.008 * \\
(0.004)\end{array}$ & $\begin{array}{l}0.008 * * \\
(0.004)\end{array}$ \\
\hline Firstborn is female*Post & & & $\begin{array}{c}-0.019 * * * \\
(0.006)\end{array}$ & $\begin{array}{c}-0.020 * * * \\
(0.006)\end{array}$ & $\begin{array}{c}0.005 \\
(0.012)\end{array}$ & \\
\hline Firstborn is female*Hindu*Post & $\begin{array}{r}-0.000 \\
(0.013)\end{array}$ & & & & & $\begin{array}{c}-0.022 * * \\
(0.011)\end{array}$ \\
\hline Firstborn is female*Hindu*Post1 & & $\begin{array}{c}0.003 \\
(0.013)\end{array}$ & & & & \\
\hline Firstborn is female*Hindu*Post2 & & $\begin{array}{r}-0.039 \\
(0.036)\end{array}$ & & & & \\
\hline State specific trends & yes & yes & yes & yes & yes & yes \\
\hline Children & 216,909 & 216,909 & 216,909 & 188,003 & 28,906 & 216,909 \\
\hline R-Squared & 0.001 & 0.001 & 0.223 & 0.219 & 0.258 & 0.223 \\
\hline
\end{tabular}

Notes: Parameter estimates reported are from linear probability model; each woman contributes $N-1$ observations, where $N$ is the number of children ever born to a woman; dependent variable in columns 1 and 2 takes value 1 if child $j$ is female, dependent variable in columns 3 to 6 takes value 1 if child $j$ has a younger sibling; Firstborn is female is a dummy taking the value 1 if the firstborn child of woman $i$ is a girl; Post is a dummy taking value 1 if child $j$ is born after 1985; Post1 is a dummy taking value 1 if child $j$ is born between 1986 and 1994; Post2 is a dummy taking value 1 if child $j$ is born between 1995 and 2005; Hindu is a dummy taking value 1 if the religion of woman $i$ is Hinduism; the sample consists of women with at least one child born before 1980 drawn from NFHS-1, NFHS-2 and NFHS-3; the sample in columns 1, 2, 3 and 6 refers to the whole of India, the sample in column 4 to Hindu women, the sample in column 5 to Muslim women; standard errors are reported in parentheses and are clustered at the state level; ***, **, and ${ }^{*}$ indicate significance at the $1 \%, 5 \%$ and $10 \%$ levels.

\subsection{Robustness}

This section investigates the robustness of the main results in three ways. As a first check, I estimate the effect of the Dowry Prohibition Rules using the complete birth history of women. For this purpose, I estimate a specification similar to the one outlined in equation 7. In this framework, each woman contributes $N-1$ observations where $N$ is the number of children ever born to her. The dependent variable takes the value 1 if at birth order $j$ a woman has another child. For each woman the dependent variable becomes a vector of 1s followed by a 0 for her last birth only. In this framework, the Dowry Prohibition Rules are captured by the double interaction between an indicator for the firstborn child being 
female $^{34}$ and a dummy for whether child $i$ is born after 1985. As before, I estimate this model for Hindus and Muslims separately and combine the estimates in a triple differences framework.

The results in columns 3 to 6 of table 8 show that even with this methodology the Dowry Prohibition Rules are found to significantly affect reproductive behaviour. Column 3 reports the difference in differences estimates, which show a decrease of 2 percentage points. This corresponds to around $25 \%$ of the pre-treatment mean. As columns 4 and 5 shows, this decrease is only significant for Hindus. The reproductive behaviour of Muslims is not affected. Finally, the triple differences estimates in column 6 show that the Dowry Prohibition Rules decreased the positive association between the firstborn child being female and fertility rates by 2.2 percentage points, which corresponds to around $25 \%$ of the pre-treatment baseline.

As a second check, I investigate the fertility behaviour of women 15 years before the policy. If the results of the main specification were driven by underlying factors, one would expect to find time trends in $\gamma_{g}$ even before the introduction of the anti-dowry law. To test this, I select women born in the years 1942 to 1948 and estimate equation 5 for the years 1966 and 1974. The results are reported in appendix A. For both Hindus (panel a) and Muslims (panel b) the parameter estimates for this specification do not vary significantly from zero. Furthermore, the timetrend in the parameter $\gamma_{g}$ appears very flat. This finding can be seen as further evidence that preferences for sons are very stable over time in India.

As a final check, I focus on the pre-treatment period and investigate whether $\gamma_{g}$ varies in the years before the policy. For this purpose, I select the same women used for the main specification and focus on the years 1981 to 1985. For this sample, I estimate placebo treatments for the years 1982 to 1985, 1983 to 1985, 1984 to 1985 and 1985. Columns 1 to 3 of appendix B report the parameter estimates for these specifications. The first row suggests that the effect of the gender of the firstborn significantly affects fertility rates. The interactions of this variable with the placebo treatments, further, indicate that the effect of $\gamma_{g}$ did not vary in the pre-treatment years. The estimates for all interactions are small in size and not statistically significant.

\section{Conclusion}

The main results of this paper suggest that the widely documented correlation between a couple's gender composition and its fertility choices is, in part, a reflection of gender differences in the economic costs of children. Two ramifications of these findings appear worthy of a short discussion. First, the relative importance of child raising costs for parents'

\footnotetext{
${ }^{34}$ I only consider births or birth order 2 or higher.
} 
reproductive behaviour raises the question whether economic factors also influence other aspects of raising children. Whilst researchers are devoting increasing interest to inheritance rights or political representation of women, human development aspects such as nutrition, weight, height and other health outcomes have remained underexplored. Bhalotra et al. (2014) take a step in this direction. Second, many previous explanations of the presence of son preferring stopping rules in fertility behaviour argued for these being the result of deeply rooted attitudes that boys are more valuable than girls. The results put forward here, by contrast, argue that a large part of this behaviour can explained by the relatively simple economic intuition that sons are cheaper to raise than girls. Moreover, if dowries affect reproductive behaviour it stands to reason that other factors influencing the net cost of children - may it be the cost or returns - can potentially influence the same processes. This is an encouraging finding for practitioners because it can constitute a new set of instruments to influence fertility decisions taken by households. Furthermore, from a political perspective, dowries have been widely criticised for their negative influence on brides. This analysis highlights a further negative unintended consequence of this already widely criticised custom. 


\section{References}

Abadian, S., "Women's autonomy and its impact on fertility," World Development, 1996, $24(12), 1793-1809$.

Aiyer, K and Tripathi, S. L., Dpwry Prohibition Act, 1961 Allied and Cognate Offences, Malhotra Law House, 1998.

Ambrus, A., E. Field, and M. Torero, "Muslim Family Law, Prenuptial Agreements, and the Emergence of Dowry in Bangladesh," Quarterly Journal of Economics, 2010, 125 (3), $1349-1397$.

Anderson, S., "Why Dowry Payments Declined with Modernization in Europe but Are Rising in India?," The Journal of Political Economy, 2003, 111 (2), 269 - 310.

_ , "The Economics of Dowry and Brideprice," Journal of Economic Perspectives, 2007, 21 (4), $151-174$.

_ , "Why the marriage squeeze cannot cause dowry inflation," Journal of Economic Theory, 2007, 137 (1), $140-152$.

Arnold, F., M. K. Choe, and T. K. Roy, "Son Preferences, the Family Building Process and Child Mortality in India," Population Studies, 2002, 52, 301 - 315.

Arokiasamy, P., "Gender Preference, Contraceptive Use and Fertility in India: Regional and Development Influences," International Journal of Population Geography, 2002, 8 (1), $49-67$.

Arunachalam, R. and T. Logan, "Is there dowry inflation in India?," NBER Working Paper No. 13905, 2008.

Barcellos, Silvia Helena, Leandro S. Cargalho, and Adriana Lleras-Muney, "Child gender and parental investments in India: Are boys and girls treated differently?," American Economic Journal: Applied Economics, 2014, 6, 157 - 189.

Basu, Deepankar and Robert De Jong, "Son Targeting Fertility Behavior: Some Consequences and Determinants," Demography, 2010, $47(2), 521-536$.

Bhalotra, S. and T. Cochrane, "Where have all the young girls gone? Identification of Sex Selection in India," IZA Working Paper, 2010, 5381. 
Bhalotra, Sonia, Abhishek Chakrabarty, and Selim Gulesci, "The Price of Gold: Dowry and Son Preference in India," mimeo, 2014.

Bhargava, A., "Family Planning, Gender Differences and Infant Mortality: Evidence from Uttar Pradesh, India," Journal of Econometrics, 2003, 112, 225 - 240.

Bhaskar, V. and B. Gupta, "India's missing firls: biology, customs, and economic development," Oxford Review of Economic Policy, 2007, 23 (2), 221 - 238.

Bhatnagar, J. P., Cases and Materials on Dowry Prohibition Act, Ashoka Law House, 1988.

Bloch, F. and V. Rao, "Terror as a Bargaining Instrument: A Case Study of Dowry Violence in Rural India," American Economic Review, 2002, 92 (4), 1029 - 1043.

_, , , and S. Desai, "Wedding Celebrations as conspicuous consumption: signaling social status in rural India," Journal of Human Resources, 2004, 39, 675 - 695.

Borooah, Vani K., "Gender bias among children in India in their diet and immunisation against disease," Social Science and Medicine, 2004, 58, 1719 - 1731.

Botticini, M. and A. Siow, "Why Dowries?" American Economic Review, 2003, 93 (4), $1385-1398$.

Brown, P. H., "Dowry and Intrahousehold Bargaining: Evidence from China," Journal of Human Resources, 2009, 44, $25-46$.

Caldwell, J. C:, P. H. Reddy, and P. Caldwell, "The causes of marriage change in South India," Population studies, 1983, 37 (3), 343 - 361.

Chaudhuri, Sanjukta, "The Desire for Sons and Excess Fertility: A Household-Level Analysis of Parity Progression in India," International Perspectives on Sexual and Reproductive Health, 2012, 38 (4), $178-186$.

Chowdhary, M., "Miles to go: An assessment of the engagement hurdles in the implementation of the anti-dowry law in India," in Werner Menski, ed., South Asians and the Dowry Problem, Bentham Books, 1998.

Dahl, G. B. and E. Moretti, "The Demand for Sons," The Review of Economic Studies, $2008,75,1085-1120$. 
Dalmia, Sonia, "A hedonic analysis of marriage transactions in India: estimating determinants of dowries and demand for groom characteristics in marriage," Research in Economics, 2004, 58, 235 - 255.

Das, Narayan, "Sex Preference and Fertility Behaviour: a Study of Recent Indian Data," Demography, 1987, 24 (4), 517 - 530.

Deininger, K., A. Goyal, and H. Nagarajan, "Women's Inheritance Rights and Intergenerational Transmission of Resources in India," Journal of Human Resources, 2013, 48, $114-141$.

Deolalikar, A. and V. Rao, The demand for dowries and bride characteristics in marriage: Empirical estimates from rural South-Central India, Oxford University Press, 1998.

Diamond-Smith, N, N Luke, and S McGarvey, "Too many girls, too much dowry': son preference and daughter aversion in rural Tamil Nadu, India," Culture, Health and Sexuality, 2008, 10 (7), $697-708$.

Diwan, Paras, Dowry and protection to married women, Deep and Deep Publications, New Delhi, 1990.

Do, Q., S. Iyer, and S. Joshi, "The economics of consanguine marriages," The Review of Economics and Statistics, 2013, 95 (3), $904-918$.

Dreze, J. and M. Murthi, "Fertility, Education and Development: Further Evidence from India," Population and Development Review, 2001, 27 (1), 33 - 63.

Edlund, L., "The Marriage Squeeze Interpretation of Dowry Inflation: A Comment," The Journal of Political Economy, 2000, 108 (6), 1327 - 1333.

_ , "The Price of Marriage: Net vs. Gross Flows and the South Indian Dowry Debate," The Journal of the European Economic Association, Papers and Proceedings, 2006, 4 (2-3), 542 -551 .

Gosh, S. K., Women and Crime, Ashish Publishing, New Delhi, 1993.

Government of India, Dowry Prohibition Act, Act No. 28 of 1961, 1961.

_, Dowry Prohibition Rules, Act No. 63 of 1984, 1985.

International Institute for Population Sciences and Macro International, "National Family Health Survey - 1," Macro International, 1994, pp. 1992 - 1993. India, Mumbai. 
_ , "National Family Health Survey - 2," Macro International, 1999, pp. 1998 - 1999. India, Mumbai.

_ , Mumbai: IIPS, 2007.

_. , "National Family Health Survey - 3," Macro International, 2007, pp. 2005 - 2006. India, Mumbai.

Jayachandran, S. and I. Kuziemko, "Why Do Mothers Breastfeed Girls Less than Boys? Evidence and Implications for Child Health in India," Quarterly Journal of Economics, 2011, 126 (3), $1485-1538$.

Jensen, R., "Equal Treatment, Unequal Outcomes? Generating Sex Inequality through Fertility Behavior," IDF Working Paper 3030, 2003.

_ , "The (Perceived) returns to education and the demand for schooling," Quarterly Journal of Economics, 2010, 125 (2), 515 - 548.

_., "Do Labor Market Opportunities Affect Young Women's Work and Family Decisions? Experimental Evidence from India," Quarterly Journal of Economics, 2012, 127 (2), 753 $-792$.

Jong, Bradford J. De, "India Since Independence: An Analytic Growth Narrative," in Dani Rodrik, ed., In Search of Prosperity: Analytic Narratives on Economic Growth, Princeton: Princeton University Press, 2003.

Kumar Gandhi, Praveen, Social Action Through Law: Partnership for Social Justice, Concept - New Delhi, 1985.

Majumdar, Maya, Encyclopaedia Of Gender Equality Through Women Empowerment, Sarup and Sons, New Delhi, 2005, 2005.

Menksi, W., "Legal Strategies for curbing the dowry problem," in Werner Menski, ed., South Asians and the Dowry Problem, Bentham Books, 1998.

Munshi, Kaivan and Mark Rosenzweig, "Traditional Institutions Meet the Modern World: Caste, Gender, and Schooling Choice in a Globalizing Economy," American Economic Review, 2006, 96 (4), 1225 - 1252.

Mutharayappa, R., M. K. Choe, F. Arnold, and T. K. Roy, "Son Preference and Its Effect on Fertility in India," NFHS Subject Reports, 1997, 3. 
Nag, M, "Sex preference in Bangladesh, India and Pakistan, and its effect on fertility," Demography India, 1991, 20 (2), 163 - 185.

National Council of Applied Economic Research, "Rural Economic and Demographic Survey," Delhi, 1999.

National Crime Reference Bureau, Crime in India, Government of India - New Delhi, 1992.

Poertner, C. C., "Sex Selective Abortions, Fertility and Birth Spacing," University of Washington, Department of Economics, Working Papers, UWEC-2010-04-R, 2010.

Qian, N., "Missing Women and the Price of Tea in China: The Effect of Sex-Specific Earnings on Sex Imbalance," Quarterly Journal of Economics, 2008, 123 (3), 1251 - 1285.

Rao, V., "The Rising Price of Husbands: A Hedonic Analysis of Dowry Increases in Rural India," The Journal of Political Economy, 1993, 101 (4), 666 - 677.

_ , "The Marriage Squeeze Interpretation of Dowry Inflation: Response," The Journal of Political Economy, 2000, 108 (6), 1334 - 1335.

Retherford, R. D. and T. K. Roy, "Factor Affecting Sex-Selective Abortion in India and 17 major states," National Family Health Survey Subject Reports No. 21. Mumbai: International Institute for Population Sciences; and Honolulu: East-West Mumbai: International Institute for Population Sciences; and Honolulu: East-West, 2003.

Rosenblum, D., "The effect of fertility decisions on excess female mortality in India," Journal of Population Economics, 2013, 26 (1), 147 - 180.

_ , "Unintended Consequences of Women's Inheritance Rights on Female Mortality in India," Dalhousie University Working Paper Series, 2013.

Roy, S., "Empowering Women? Inheritance Rights, Female Education and Dowry Payments in India," Cage Online Working Paper Series, 2011.

Seidl, C., "The desire for a son is the father of many daughters. A sex ratio paradox," Journal of Population Economics, 185 - 203 1995, 8.

Tertilt, Michele, "Polygyny, Fertility, and Savings," Journal of Political Economy, 2005, 113 (6), $1341-1371$.

The World Bank, World Development Report: Gender Equality and Development, The World Bank, 2012. 
Virmani, Arvind, "India's economic growth: From socialist rate of growth to Bharatiya rate of growth," ICRIER Working Paper Series, 2004, 122.

_ , "Sources of India's economic growth: Trends in total factor productivity," ICRIER Working Paper Series, 2004, 131.

Vogl, Tom S., "Differential Fertility, Human Capital, and Development," Review of Economic Studies, 2016, 83, $365-401$.

Yamaguchi, K., "A Formal Theory for Male-Preferring Stopping Rules of Childbearing: Sex Differences in Birth Order and in the Number of Siblings," Demography, 1989, 26, 451 -65 . 


\section{A Gender of first child and yearly birth rates (1969 to 1979)}

(a) Hindus

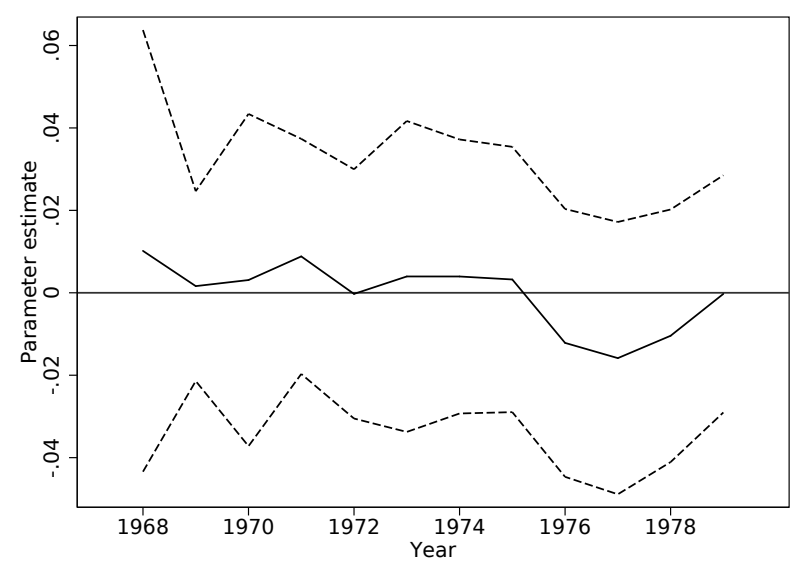

(b) Muslims

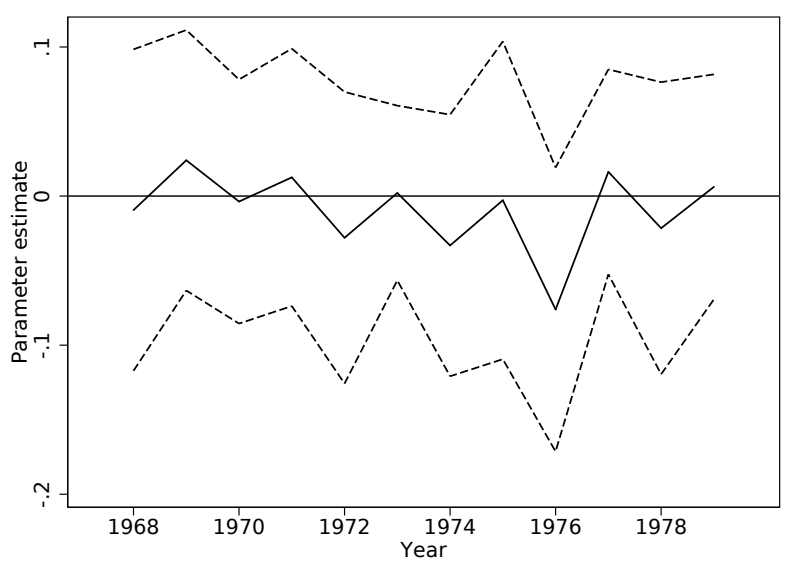

Notes: Parameter estimates reported are from linear probability model; each woman contributes 13 observations, one for each year between 1967 and 1979; dependent variable takes value 1 if woman gives birth in year $t$; the estimates refer to the interaction between the girl dummy and year dummy; mother level covariates include education, religion, caste, rural dummy, married dummy and dummies for birth cohort; sample consists of women born between 1942 and 1960 with at least one child born before 1967 drawn from NFHS-1, NFHS-2 and NFHS-3; the base year is 1967; the solid line indicates point estimates, the dashed line indicates $95 \%$ confidence interval; standard errors are clustered at the state level. 


\section{B Placebo treatments before 1985}

Table 9: Robustness

\begin{tabular}{|c|c|c|c|}
\hline & (1) & $(2)$ & $(3)$ \\
\hline & \multicolumn{3}{|c|}{$\begin{array}{l}\text { Dependent variable: } \\
\text { Probability of birth }\end{array}$} \\
\hline Firstborn is female & $\begin{array}{c}0.009 \\
(0.010)\end{array}$ & $\begin{array}{c}0.006 \\
(0.010)\end{array}$ & $\begin{array}{c}0.005 \\
(0.007)\end{array}$ \\
\hline Firstborn is female*Hindu* $(1982-1985)$ & $\begin{array}{c}0.005 \\
(0.010)\end{array}$ & & \\
\hline Firstborn is female*Hindu*(1983-1985) & & $\begin{array}{c}0.001 \\
(0.010)\end{array}$ & \\
\hline Firstborn is female*Hindu*(1984-1985) & & & $\begin{array}{r}-0.001 \\
(0.009)\end{array}$ \\
\hline Observations & 264,612 & 264,612 & 264,612 \\
\hline Mothers & 44,102 & 44,102 & 44,102 \\
\hline R-Squared & 0.039 & 0.039 & 0.039 \\
\hline
\end{tabular}

Notes: Parameter estimates reported are from linear probability model; in colulmns 1 to 4 each woman contributes 6 observations, one for each year between 1980 and 1985, in column 5 each woman contributes 10 observations, one for each year between 1980 and 1989; dependent variable takes value 1 if woman gives birth in year $t$; mother level covariates include education, religion, caste, rural dummy, married dummy and dummies for birth cohort; variable post is a dummy for $t \geq 1986$; sample consists of women born between 1949 and 1964 with at least one child born before 1980 drawn from NFHS-1, NFHS-2 and NFHS-3; standard errors are reported in parentheses and are clustered at the state or mother level; ${ }^{* * *},{ }^{* *}$, and ${ }^{*}$ indicate significance at the $1 \%, 5 \%$ and $10 \%$ levels. 